\title{
Support System Effects on the DLR-F6 Transport Configuration in the National Transonic Facility
}

\author{
Melissa B. Rivers ${ }^{1}$, Craig A. Hunter ${ }^{2}$ and Gregory M. Gatlin ${ }^{3}$ \\ NASA Langley Research Center, Hampton, VA 23681
}

An experimental investigation of the DLR-F6 generic transport configuration was conducted in the NASA NTF for use in the Drag Prediction Workshop. As data from this experimental investigation was collected, a large difference in drag values was seen between the NTF test and an ONERA test that was conducted several years ago. After much investigation, it was determined that this difference was likely due to a sting effect correction applied to the ONERA data which NTF does not use. This insight led to the present work. In this study, a computational assessment has been undertaken to investigate model support system interference effects on the DLR-F6 transport configuration. The configurations computed during this investigation were the isolated wing-body, the wing-body with the full support system (blade and sting), the wing-body with just the blade, and the wing-body with just the sting. The results from this investigation show the same trends that ONERA saw when they conducted a similar experimental investigation in the S2MA tunnel. Computational results suggest that the blade contributed an interference type of effect, the sting contributed a general blockage effect, and the full support system combined these effects.

\begin{tabular}{|c|c|}
\hline & Nomenclature \\
\hline$b$ & $=$ wing span, in. \\
\hline$C$ & $=$ wing mean aerodynamic chord, in. \\
\hline$C_{D}$ & $=$ drag coefficient \\
\hline$C_{L}$ & $=$ lift coefficient \\
\hline$C_{m}$ & $=$ pitching-moment coefficient referenced to 0.25 of the wing mean aerodynamic chord \\
\hline$C_{p}$ & $=$ pressure coefficient \\
\hline CFD & $=$ computational fluid dynamics \\
\hline CFL & $=$ Courant, Freidrichs, and Lewy \\
\hline$D L R$ & $=$ German Aerospace Center \\
\hline$D P W$ & $=$ Drag Prediction Workshop \\
\hline$M$ & $=$ Freestream Mach number \\
\hline NASA & $=$ National Aeronautics and Space Administration \\
\hline NTF & $=$ National Transonic Facility \\
\hline ONERA & $=$ The French Aerospace Lab \\
\hline$R e_{c}$ & $=$ Reynolds number based on mean aerodynamic chord \\
\hline$S$ & $=$ model reference area, $\mathrm{ft}^{2}$ \\
\hline$y^{+}$ & $=$Non-dimensional law of the wall boundary layer coordinate \\
\hline$\alpha$ & $=$ angle of attack, deg. \\
\hline
\end{tabular}

\section{Introduction}

Tn an effort to assess the state of the art in computational fluid dynamics (CFD) drag prediction, the AIAA Applied Aerodynamics Technical Committee has initiated a series of Drag Prediction Workshops. The goal of the workshops is to assess state-of-the-art computational methods as practical aerodynamic tools for aircraft force and moment prediction of industry relevant geometries, with a focus on drag prediction. Furthermore, the Drag Prediction Workshop (DPW) is designed to serve as an impartial forum for evaluating the effectiveness of existing computational Navier-Stokes solvers and modeling techniques, and is intended to promote an open discussion on areas needing additional research and development. In order to encourage the widest participation, public-domain subject geometries have been used that are industry-relevant, yet simple enough to permit high-fidelity computations. Additionally, baseline grids have been provided to reduce the variability of CFD results.

\footnotetext{
${ }^{1}$ Research Engineer, Configuration Aerodynamics Branch, Mail Stop 267, Senior Member AIAA.

${ }^{2}$ Research Engineer, Configuration Aerodynamics Branch, Mail Stop 499.

${ }^{3}$ Research Engineer, Configuration Aerodynamics Branch, Mail Stop 267, Senior Member AIAA.
} 
The first drag prediction workshop (DPW-I) ${ }^{1,2}$, held in June of 2001, was directed at the calculation of a wing/body commercial transport configuration, known as the DLR-F4 ${ }^{3,4}$. Previously obtained experimental data were available to compare to for this first workshop. Predictions of a cruise polar and drag rise were the focus. The second drag prediction workshop (DPW-II) ${ }^{5,6}$, held in June of 2003, added the challenge of determining the increment of a large component, in this case a pylon/nacelle. The DLR-F6 configuration ${ }^{5,7}$ was used for this study. Once again, experimental data were available for comparison.

The third drag prediction workshop (DPW-III) ${ }^{8,9}$, held in June of 2006, added the challenge of determining the increment due to adding a small component, in this case a wing/body fairing. However for this workshop, calculations were conducted "blind" with no experimental data available for comparison. It is these blind calculations that draw the connection between the third drag prediction workshop and the recent experimental investigation of the DLR-F6 in the National Transonic Facility (NTF). The force and moment, surface pressure, model deformation, and surface flow visualization data obtained in the NTF wind tunnel investigation, and presented in References 10 and 11, have served as the validation data for the third drag prediction workshop. The results presented in this paper, addressing model support system effects, serve as an addendum to the results obtained for the DPW-III.

\section{Background}

\section{A. Facility Description}

The $\mathrm{NTF}^{12}$ is a unique national facility (Figure 1) that enables testing of aircraft configurations at conditions ranging from subsonic to low supersonic speeds, at Reynolds numbers up to full-scale flight values. The NTF is a conventional, closed circuit, continuous-flow, fan-driven wind tunnel (Figure 2) capable of operating in either dry air at warm temperatures or nitrogen from warm to cryogenic temperatures. Elevated pressure in combination with cryogenic temperature enables testing to the highest Reynolds numbers.

The test section is $8.2 \times 8.2 \times 25 \mathrm{ft}$ and has a slotted floor and ceiling. Turbulence is reduced by four damping screens in the settling chamber and a contraction ratio of 14.95:1 from the settling chamber to the nozzle throat. Fan-noise effects are minimized by acoustic treatment both upstream and downstream of the fan. Thermal insulation resides inside the pressure shell to aid in maintaining tunnel temperature and thus minimize energy consumption.

The NTF has an operating pressure range of approximately 15 to 125 psia, a temperature range of -260 to +120 ${ }^{\circ} \mathrm{F}$, and a Mach number range of 0.2 to 1.2 . The maximum Reynolds number per foot is $146 \times 10^{6}$ at Mach 1 . When the tunnel is operated cryogenically, heat is removed by the evaporation of liquid nitrogen, which is sprayed into the tunnel circuit upstream of the fan. During this operational mode, venting is necessary to maintain a constant total pressure. When air is the test gas, heat is removed from the system by a water-cooled heat exchanger at the upstream end of the settling chamber. Further tunnel details and facility information are provided in Reference 13.

\section{B. Model Description}

The wind tunnel model used in the current investigation is a refurbished DLR-F6 model. This configuration, representative of a modern, twin-engine, transport aircraft, is a transonic wing-body design derived from the earlier DLR-F4 configuration. The DLR-F6 model was originally built in the 1980's and subsequently tested in several investigations at the French ONERA S2MA wind tunnel. The DLR-F6 is designed for a cruise Mach number of $\mathrm{M}=0.75$ and a design lift coefficient of $\mathrm{C}_{\mathrm{L}}=0.5$.

A three-view sketch of the model showing the overall dimensions is given in Figure 3. The aspect ratio is 9.5, the leading edge sweep angle is $27.1^{\circ}$, the wing reference area (S) is $225.370 \mathrm{in}^{2}$, the wing span (b) is 46.114 inches, and the mean aerodynamic chord (c) is 5.559 inches. The model moment reference center is located 19.878 inches back from the fuselage nose and 1.336 inches below the fuselage centerline.

The DLR-F6 model consists of a carbon fiber reinforced polymer fuselage and a pair of steel wings, both of which are bolted to an internal steel balance block. In addition, the DLR-F6 model can be equipped with flowthrough nacelles, as described in Reference 10. The flow-through nacelles, however, were not incorporated into the current computational study. Pressure distributions are measured on the right wing by 288 pressure orifices located in 8 span-wise wing sections. All pressure measurements were made using Electronically Scanned Pressure (ESP) modules mounted inside the forward portion of the fuselage.

A new blade sting was designed and built by NASA for installation of the DLR-F6 model in the NTF. Not only did this blade sting provide the proper interface between NASA's NTF-104B strain gauge balance and the NTF arc sector model support structure, it also was designed to match as closely as possible the blade sting used in the previous tests in the ONERA S2MA wind tunnel. Due to the higher load requirements for the NTF test, the blade on 
the new NASA sting was approximately 1.3 inches longer in the streamwise direction, and approximately one-eighth inch wider at the location where it enters the fuselage. A set of sting blade inserts made of carbon fiber composite and shaped close to the surface of the NTF sting blade was prepared by DLR. During the final test preparation at the NTF, the gap between the fuselage inserts and the sting blade was carefully sealed by use of a small custom-made glass fiber fabric seal. Special care was taken to ensure the gap was sealed without creating any forces between the non-metric sting blade and the metric fuselage inserts. A photograph of the DLR-F6 model as it was mounted in the test section of the NTF is presented in Figure 4.

\section{Test Conditions}

The investigation, conducted over a 4-week period, provided force and moment, surface pressure, model deformation, and surface flow visualization data. Testing was conducted at 3 million chord Reynolds number to compare with previously existing data, and also at 5 million chord Reynolds number such that an assessment of Reynolds number effects could be made (albeit over a small range). Due to strength limitations of the model and the requirement to obtain data at an increased Reynolds number of 5 million, all testing was conducted at a freestream total temperature of $40^{\circ} \mathrm{F}$ in nitrogen gas. Testing at this moderately reduced temperature allowed for a 5 million Reynolds number condition without requiring a dynamic pressure that would have exceeded model strength limitations. Although data were obtained at both 3 and 5 million Reynolds number for the wing-body configuration, only data obtained at 3 million Reynolds number will be presented for comparison with the computational study presented herein.

All data presented in this paper were obtained at a freestream Mach number of 0.75 . Data were generally obtained over an angle-of-attack range from $-4^{\circ}$ to $+2^{\circ}$ at 3 million Reynolds number and from $-4^{\circ}$ to $+1^{\circ}$ at 5 million Reynolds number. The reduced angle-of-attack range at 5 million Reynolds number was required so that safe model stress levels would not be exceeded.

Flow angularity measurements were made and upflow corrections ranging from $0.15^{\circ}$ to $0.185^{\circ}$ were applied to the final data. Classical wall corrections accounting for model blockage, wake blockage, tunnel buoyancy, and lift interference have been applied according to the methods presented in Reference 14.

\section{Comparison with ONERA Data and Support System Corrections}

As discussed in the previous study ${ }^{10}, a \sim 10$ count difference in minimum drag was noted when NTF and ONERA drag coefficient data were compared for the DLR-F6 wing-body configuration (see Figure 5). Upon investigation, it was determined that a sting correction to axial force had been applied to the ONERA data. At the minimum drag coefficient, the ONERA sting correction increased drag by 11 drag counts, and explains the difference compared to the NTF data (which did not use a sting correction).

\section{Computational Approach}

\section{A. Flow Solver}

The NASA Langley unstructured computational fluid dynamics code USM3D 6.0 ${ }^{15-18}$ was used for Navier-Stokes analysis in this study. Within the tetrahedral cell-centered, finite volume flow solver, inviscid flux quantities are computed across each cell face using one of the following schemes: Roe's flux-difference splitting (FDS), Advection Upstream Splitting Method (AUSM), Flux Vector Splitting (FVS), or Harten, Lax, and van Leer with Contact restoration (HLLC). A novel reconstruction process is used for spatial discretization, based on an analytical formulation for computing gradients within tetrahedral cells. Solutions are advanced to a steady state condition using an implicit backward-Euler time-stepping scheme. For numerical stability, limiter options include MinMod and Superbee flux limiters and an Eigen-value limiter. Turbulence closure in USM3D 6.0 is given by the one equation Spalart-Allmaras (SA) model, the two-equation k- $\varepsilon$ turbulence model, or the two-equation Menter SST model. For the present study, FDS and Spalart-Allmaras were used. To improve the prediction of skin friction drag, a solution limiter was not activated.

\section{B. Grid Generation}

The VGRID/GridTool software system ${ }^{19}$ was used to generate unstructured grids for this study. VGRID uses an advancing-front method for generating Euler tetrahedral grids, and an advancing-layer method for thin-layer tetrahedral viscous grids required for Navier-Stokes analysis. In defining the computational domain, boundaries are represented by bi-linear surface patches that are constructed in GridTool based on user-specified geometries and an 
IGES definition. Grid characteristics like cell spacing and stretching are also specified in GridTool by the placement of volume, node, and linear sources.

A surface mesh is generated in VGRID by triangulating each surface patch with a two-dimensional version of the advancing-front method. Triangulated surface patches then form the initial front for the generation of threedimensional tetrahedral volume cells by the advancing-layer and advancing-front methods. Smooth variation of grid spacing is achieved with an exponential growth function, using the GridTool-defined sources as inputs.

Four semi-span grids were developed for this study: a grid containing the isolated wing-body, a grid containing the wing-body and support blade, a grid containing the wing-body and support sting, and a grid containing the wingbody and full support system (blade and sting). Surface meshes from each grid are shown in figures 6-9. Grid sizes ranged from 19.7 million cells for the isolated wing body to 29.4 million cells for the wing-body with full support system. Boundary layers were resolved using approximately 32 cells, with a first cell height at $\mathrm{y}^{+}$of 0.5 . In all cases, the computational domain extended roughly 10 body lengths from the aircraft fuselage in all directions.

\section{Boundary Conditions}

Outer boundaries of the computational domain were treated as characteristic inflow/outflow surfaces with freestream conditions specified by Mach number, Reynolds Number, flow angle, and static temperature. For comparison with wind tunnel data, a freestream Mach number of 0.75 and a Reynolds number of 3 million were chosen. Solutions were run over a range of angles of attack from $0^{\circ}$ to $1.2^{\circ}$.

A reflection boundary condition was used at the symmetry plane of the semi-span geometry. All other aircraft and model support system surfaces were treated as no-slip viscous boundaries.

\section{Solution Procedure}

Solutions presented in this paper were obtained by running USM3D on the Columbia supercomputer at NASA's Advanced Supercomputing Division (NAS), using 48 processors. Cases typically needed 10,000 cycles for full convergence, requiring 5 to 11 hours of wall-clock time. During the computation, global CFL number ramped from 1 to 50. Convergence was judged by tracking the solution residual and integrated aerodynamic performance coefficients until they settled out in a satisfactory fashion. A typical convergence history is shown in figure 10.

\section{E. Force and Moment Integration}

Forces and moments were computed within the flow solver by evaluating pressure and skin friction on the surface. Force coefficients given in this paper were computed for the aircraft (wing-body) by itself. Forces on the support system components were ignored. Because the contribution of forces in the small area where the blade intersected the aircraft fuselage were negligible, no attempt was made to book-keep or correct for these forces when comparing configurations with and without the blade.

\section{Results and Discussion}

This study consisted of computing cases at a Mach number of 0.75 and a Reynolds number of 3 million. The solutions were run over a range of angles of attack from 0 to 1.2. The results shown in this paper concentrate on the $\mathrm{M}=0.75, \mathrm{Re}_{\mathrm{c}}=3 \times 10^{6}$, and $\alpha=0.0^{\circ}$ cases, though some additional cases will be shown at $\mathrm{C}_{\mathrm{L}}=0.5$. Summary results from the $\alpha=0.0^{\circ}$ cases are shown in Table 1 below, along with reference data points from experimental data in the same range of $\alpha$ and $\mathrm{C}_{\mathrm{L}}$ :

Table 1: Summary of $\alpha=0.0^{\circ}$ Cases

\begin{tabular}{|l|c|c|c|c|c|c|c|}
\hline Case & Mach & $\mathbf{R e}_{\mathbf{c}} / \mathbf{1 0}^{\mathbf{6}}$ & $\boldsymbol{\alpha}$ & $\mathbf{C}_{\mathbf{L}}$ & $\mathbf{C}_{\mathbf{D}}$ & $\Delta \mathbf{C}_{\mathbf{L}}$ & $\Delta \mathbf{C}_{\mathbf{D}}$ \\
\hline USM3D Isolated Wing Body & 0.75 & 3.0 & 0.00 & 0.4806 & 0.0281 & 0.0000 & 0.0000 \\
\hline USM3D Wing Body w/ Blade & 0.75 & 3.0 & 0.00 & 0.4691 & 0.0288 & -0.0115 & 0.0007 \\
\hline USM3D Wing Body w/ Sting & 0.75 & 3.0 & 0.00 & 0.4743 & 0.0268 & -0.0063 & -0.0013 \\
\hline USM3D Wing Body w/ Full Support & 0.75 & 3.0 & 0.00 & 0.4635 & 0.0275 & -0.0170 & -0.0006 \\
\hline NTF Test 179 Run 51 & 0.75 & 3.0 & -0.056 & 0.4175 & 0.0257 & NA & NA \\
\hline NTF Test 179 Run 51 & 0.75 & 3.0 & 0.692 & 0.5084 & 0.0292 & NA & NA \\
\hline
\end{tabular}

Figures 11-14 show surface pressure coefficient $\left(\mathrm{C}_{\mathrm{P}}\right)$ contours for the four configurations. Each of the three support system variations will be discussed separately below. In general, though, these figures show that adding a blade, sting, and full support system does change the surface pressures, although in different areas for each configuration. 
To better understand variations in surface pressure, the change in pressure coefficient $\left(\Delta \mathrm{C}_{\mathrm{P}}\right)$ is also examined. This is obtained by subtracting the isolated wing-body configuration's surface pressure coefficient from each support configuration's surface pressure coefficient. This can be studied in even more detail by breaking $\Delta \mathrm{C}_{\mathrm{P}}$ out into its lift and drag contributions. These quantities are obtained by multiplying $\Delta \mathrm{C}_{\mathrm{P}}$ by a dot product between the local surface normal unit vector and a unit vector in the lift- and drag-directions, respectively. This results in plots of lift coefficient and drag coefficient per-unit-area (i.e., the integrands in lift and drag force integrations), but it is equally effective to think of these quantities as the influence of $\Delta \mathrm{C}_{\mathrm{P}}$ in the respective force directions.

\section{A. Wing-Body with Blade Configuration}

Figure 15 presents $\Delta C_{\mathrm{P}}$ for the first variation, which is the wing-body with blade configuration. This figure shows a significant change in loads in the aft fuselage region (where the blade attaches to the fuselage), but smaller, barely noticeable, changes in the wing-body junction separation region and in the wing shock area.

Figure 16 shows $\Delta \mathrm{C}_{\mathrm{L}}$ for the wing-body with blade configuration, and figure 17 shows $\Delta \mathrm{C}_{\mathrm{D}}$ (note that these plots have different contour ranges and scales than $\Delta \mathrm{C}_{\mathrm{P}}$ ). Here, the effects of the blade become much more apparent - it results in significant local lift per-unit-area changes (both positive and negative) in the aft fuselage and tail cone area, in the upper surface wing-body junction area, and in the upper surface wing shock region.

Small increases in drag per-unit-area occur on the lower surface of the tail cone, but are spread out over a large area and would have a notable effect on drag. The biggest per-unit-area changes in drag occur in the wing shock region (positive) and the wing-body junction area (positive and negative), where a known separation bubble exists. Figure 18 shows surface streamlines in this area, and it can be seen that the presence of the blade indeed changes flow in the wing-body junction region, slightly enlarging the separation bubble.

In terms of net force coefficients, the wing-body with blade configuration had a reduction in lift coefficient of $\Delta \mathrm{C}_{\mathrm{L}}=-0.0115$ and an increase in drag coefficient of $\Delta \mathrm{C}_{\mathrm{D}}=0.0007$ relative to the isolated wing-body case. This reduction in lift and increase in drag is consistent with experimental results reported by Piat and Esteve ${ }^{20}$ when testing a similar Airbus A310 model with a dummy blade attached. Overall, the presence of the blade seems to have caused a basic interference type effect; namely, attaching the blade to the aft fuselage region changed flow about the entire configuration. Variations in $C_{P}, C_{L}$, and $C_{D}$ over the entire configuration suggest numerous minor local changes took place in the flow.

\section{B. Wing-Body with Sting Configuration}

Figure 19 shows $\Delta \mathrm{C}_{\mathrm{P}}$ for the wing-body with sting configuration. $\Delta \mathrm{C}_{\mathrm{L}}$ and $\Delta \mathrm{C}_{\mathrm{D}}$ plots are shown in figures 20 and 21 , respectively. The sting has a noticeable effect on the wing upper surface shock region (most clearly visible in $\Delta \mathrm{C}_{\mathrm{L}}$ ) but very little large scale effect on the fuselage. However, zooming in closer to the tail cone region (figure 22) shows an extended area of mild drag reduction and a strong drag decrease right at the tip of the tail cone. Unlike the blade case, there was no real change in the wing-body junction region with the sting.

Knowing transonic wing shock position is very sensitive to global flow conditions, in combination with the lack of other localized changes over the configuration save for the tail cone region, suggests that the presence of the sting caused a general one-dimensional volumetric blockage type of effect. This likely would have raised pressure in the tail cone area, contributing to the drag per-unit-area reduction shown in figure 22.

Compared to the isolated wing-body case, the wing-body with sting configuration had a reduction in lift coefficient of $\Delta \mathrm{C}_{\mathrm{L}}=-0.0063$ and a reduction in drag coefficient of $\Delta \mathrm{C}_{\mathrm{D}}=-0.0013$. As before, the reduction of lift and drag due to the sting is consistent with dummy sting results of Piat and Esteve ${ }^{20}$. Note also that the reduction in drag of 13 counts is in the range of the 11 count sting correction applied by ONERA to their DLR-F6 drag data.

\section{Wing-Body with Full Support Configuration}

$\Delta \mathrm{C}_{\mathrm{P}}$ for the wing-body with full (blade and sting) support system configuration is shown in figure 23. Corresponding $\Delta \mathrm{C}_{\mathrm{L}}$ and $\Delta \mathrm{C}_{\mathrm{D}}$ plots are given in figures 24 and 25 , respectively. Here, it is obvious that the full support configuration contains characteristics from both of the simpler cases, showing changes in the wing shock, wing-body junction, aft-fuselage, and tail cone areas. Net force coefficients confirm this, with full support system numbers a near-perfect superposition of increments from the simpler blade-alone and sting-alone cases. The full support case's $\Delta \mathrm{C}_{\mathrm{L}}=-0.0170$ is very close to a combined $\Delta \mathrm{C}_{\mathrm{L}}$ of $-0.0115-0.0063=-0.0178$ from the two simpler cases. The full support case's $\Delta \mathrm{C}_{\mathrm{D}}=-0.0006$ is identical (to four decimal places) to a combined $\Delta \mathrm{C}_{\mathrm{D}}$ of 0.0007 $0.0013=-0.0006$ from the two simpler cases. This supports the notion that unique, independent effects were caused by the blade (an interference effect) and sting (a blockage effect) at the flow conditions evaluated. As in the simpler cases, lift and drag increments are in agreement with dummy blade-sting results from Piat and Esteve ${ }^{20}$. 


\section{Additional Cases at $\mathbf{C}_{\mathrm{L}} \approx 0.5$ Equivalent Flow Conditions}

The four configurations were run at $\alpha=0.184^{\circ}$, corresponding to $C_{L} \approx 0.5$ for the isolated wing-body case $\left(C_{L}=0.5\right.$ is the design lift coefficient of the DLR-F6 and was a case of interest in the drag prediction workshop). Results from those cases are summarized in Table 2 along with relevant NTF data:

Table 2: Summary of $\alpha=0.184^{\circ}$ Cases

\begin{tabular}{|l|c|c|c|c|c|c|c|}
\hline Case & $\mathbf{M a c h}$ & $\mathbf{R e}_{\mathbf{c}} / \mathbf{1 0}^{\mathbf{6}}$ & $\alpha$ & $\mathbf{C}_{\mathbf{L}}$ & $\mathbf{C}_{\mathbf{D}}$ & $\Delta \mathbf{C}_{\mathbf{L}}$ & $\Delta \mathbf{C}_{\mathbf{D}}$ \\
\hline USM3D Isolated Wing Body & 0.75 & 3.0 & 0.184 & 0.5002 & 0.0290 & 0.0000 & 0.0000 \\
\hline USM3D Wing Body w/ Blade & 0.75 & 3.0 & 0.184 & 0.4976 & 0.0297 & -0.0026 & 0.0007 \\
\hline USM3D Wing Body w/ Sting & 0.75 & 3.0 & 0.184 & 0.4954 & 0.0278 & -0.0047 & -0.0013 \\
\hline USM3D Wing Body w/ Full Support & 0.75 & 3.0 & 0.184 & 0.4912 & 0.0284 & -0.0089 & -0.0006 \\
\hline NTF Test 179 Run 51 & 0.75 & 3.0 & -0.056 & 0.4175 & 0.0257 & NA & NA \\
\hline NTF Test 179 Run 51 & 0.75 & 3.0 & 0.692 & 0.5084 & 0.0292 & NA & NA \\
\hline NTF 179 / 51, Interpolation to $C_{\mathbf{L}}=0.5000$ & 0.75 & 3.0 & 0.618 & 0.5000 & 0.0288 & NA & NA \\
\hline NTF 179 / 51, Interpolation to $C_{L}=0.4912$ & 0.75 & 3.0 & 0.540 & 0.4912 & 0.0284 & NA & NA \\
\hline
\end{tabular}

These runs show the effect of the various support system configurations at the same flow conditions (namely $\alpha$, such that incidence is constant) where the isolated wing-body configuration has a lift coefficient of 0.5 . It's worth noting that the same $\Delta \mathrm{C}_{\mathrm{L}}$ and $\Delta \mathrm{C}_{\mathrm{D}}$ trends exist at this slightly higher angle of attack as were identified at $\alpha=0.0^{\circ}$, but it's also important to interpret the results in a more fundamental way. Specifically, by considering that running the isolated wing body configuration at $\mathrm{C}_{\mathrm{L}} \approx 0.5$ corresponds to running the full sting and blade support case at lower $\mathrm{C}_{\mathrm{L}}$ and lower $C_{D}$ (again assuming that flow incidence is considered a relevant parameter to hold constant when evaluating support system effects). Here, a relatively minor $\Delta \mathrm{C}_{\mathrm{L}}=+0.0089$ lift correction and a fairly significant $\Delta \mathrm{C}_{\mathrm{D}}=+0.0006$ (6 count increase) drag correction would need to be applied to the full support configuration to approximate isolated wing-body results at the same angle of attack of $\alpha=0.184^{\circ}$.

\section{Conclusion}

A computational assessment has been conducted in an effort to investigate model support system interference effects on the DLR-F6 transport configuration. The configurations computed during this investigation were an isolated wing-body, the wing-body with blade, the wing-body with sting, and the wing-body with full support system (blade and sting). The configurations were compared at common angles of attack.

Results from this investigation show the same trends that ONERA obtained when they conducted a similar experimental investigation on their model support systems. The presence of the blade resulted in a small decrease in lift and an increase in drag of about 7 counts. The presence of the sting resulted in a small decrease in lift and a decrease in drag of 13 counts. The full support system resulted in a small decrease in lift and net decrease in drag of 6 counts.

Computational results suggest that the blade contributed an interference type of effect, altering surface pressure in the aft-fuselage and tail cone regions of the configuration, as well as on the wing upper surface. The sting contributed a general blockage effect, changing the wing shock and pressurizing the tail cone region. The full support system combined these effects.

Several important points arise from the results discussed in this paper. First and foremost, these results suggest that the model support system for the DLR-F6 configuration tested in the NTF indeed affects measured aerodynamic performance. While a more rigorous computational study is needed to further classify support system effects over a wider range of flow conditions, the current results indicate the need to either develop support system corrections for NTF data or include the support system in computational studies attempting to predict the DLR-F6 configuration. The corrections or predictions need to include both the sting and blade (i.e., the full support system) because both contribute to the overall effect, combining for the lift increment and partially cancelling for the drag increment.

A ramification of the previous point is that past DPW predictions on the isolated wing-body configuration likely should not be in agreement with NTF data that contains uncorrected support system effects. Though it is not completely reasonable to base correction estimates on the results of a single CFD code used in this small-scale effort, the current study suggests that isolated wing-body CFD predictions should expect drag to be about 6 counts higher than uncorrected (for support system effects) NTF data with lift coefficients in the range of 0.5 and angle of attack in the range of about 0.0 to $0.2^{\circ}$. 


\section{References}

${ }^{1}$ Levy, D. W., Vassberg, J. C., Wahls, R. A., Zickhur, T., Agrawal, S., Pirzadeh, S., and Hemsch, M. J., "Summary of Data from the First AIAA CFD Drag Prediction Workshop,” AIAA Paper 2002-0841, January 2002.

${ }^{2}$ Hemsch, M. J., "Statistical Analysis of CFD Solutions from the Drag Prediction Workshop," AIAA Paper 2002-0842, January 2002.

${ }^{3}$ Redeker, G., Schmidt, N., and Müller, R., "Design and Experimental Verification of a Transonic Wing for a Transport Aircraft," Proceedings of the FDP Symposium on Subsonic/Transonic Configuration Aerodynamics, AGARD CP 285, 1980, pp. 13.1-13.7.

${ }^{4}$ Redeker, G., "DLR-F4 Wing Body Configuration," A Selection of Experimental Test Cases for the Validation of CFD Codes, AGARD Report AR-303, Vol. 2, 1994, pp. B4-1-21.

${ }^{5}$ Laflin, K. R., Vassberg, J. C., Wahls, R. A., Morrison, J. H., Brodersen, O., Radowitz, M., Tinoco, E. N., and Godard, J., "Summary of Data from the Second AIAA CFD Drag Prediction Workshop," AIAA Paper 2004-0555, January 2004.

${ }^{6} \mathrm{Hemsch}$, M. J. and Morrison, J. H., "Statistical Analysis of CFD Solutions from the 2nd Drag Prediction Workshop," AIAA Paper 2004-0556, January 2004.

${ }^{7}$ Rossow, C.-C., Godard, J.-L., Hoheisel, H., and Schmitt, V., "Investigations of Propulsion Integration Interference Effects on a Transport Aircraft Configuration," Journal of Aircraft, Vol. 31, No. 5, 1994, pp. 1022-1030.

${ }^{8}$ Vassberg, J. C., Tinoco, E. N., Mani, M., Broderson, O. P., Eisfeld, B., Wahls, R. A., Morrison, J. H., Zickuhr, T., Laflin, K. R., and Mavriplis, D. J., "Summary of the Third AIAA CFD Drag Prediction Workshop," AIAA Paper 2007-0260, January 2007.

${ }^{9}$ Morrison, J. H. and Hemsch, M. J., "Statistical Analysis of CFD Solutions from the Third AIAA Drag Prediction Workshop," AIAA Paper 2007-0254, January 2007.

${ }^{10}$ Gatlin, G. M., Rivers, M. B., Goodliff, S. L., Rudnik, R., and Sitzmann, M., "Experimental Investigation of the DLR-F6 Transport Configuration in the National Transonic Facility," AIAA Paper 2008-6917, August 2008.

${ }^{11}$ Burner, A. W., Goad, W. K., Massey, E. A., Goad, L. R., Goodliff, S. L., and Bissett, O. W., "Wing Deformation Measurements of the DLR-F6 Transport Configuration in the National Transonic Facility," AIAA Paper 2008-6921, August 2008.

${ }^{12}$ Gloss, B. B., "Current Status and Some Future Test Directions for the US National Transonic Facility. Wind Tunnels and Wind Tunnel Test Techniques," Royal Aeronautical Society, 1992, pp. 3.1-3.7.

${ }^{13}$ Fuller, D. E., "Guide for Users of the National Transonic Facility," NASA TM-83124, 1981.

${ }^{14}$ Iyer, V., "A Wall Correction Program Based on Classical Methods for the National Transonic Facility (Solid Wall or Slotted Wall) and the 14x22-Ft Subsonic Tunnel at NASA LaRC." NASA/CR-2004-213261, October 2004.

${ }^{15}$ Pandya, M., Abdol-Hamid, K., and Frink, N. "Enhancement of USM3D Unstructured Flow Solver for High-speed HighTemperature Shear Flows". AIAA-2009-1329, January 2009.

${ }^{16}$ Pandya, M., Abdol-Hamid, K., Campbell, R., and Frink, N. "Implementation of Flow Tripping Capability in the USM3D Unstructured Flow Solver". AIAA-2006-919, January 2006.

${ }^{17}$ Pandya, M., Frink, N., and Noack, R. "Progress Toward Overset-Grid Moving Body Capability for USM3D Unstructured Flow Solver". AIAA-2005-5118, June 2005.

${ }^{18}$ Pandya, M., Frink, N., Abdol-Hamid, K., and Chung, J. "Recent Enhancements to USM3D Unstructured Flow Solver for Unsteady Flows". AIAA-2004-5201, August 2004.

${ }_{19}$ Pirzadeh, S. "Advanced Unstructured Grid Generation for Complex Aerodynamics Applications". AIAA-2008-7178, August 2008.

${ }^{20}$ Piat, J.F. and Esteve, N. "Recent Experiments with New Twin-Sting Supports in Onera's Large Wind Tunnels". AIAA2002-2921, June 2002. 


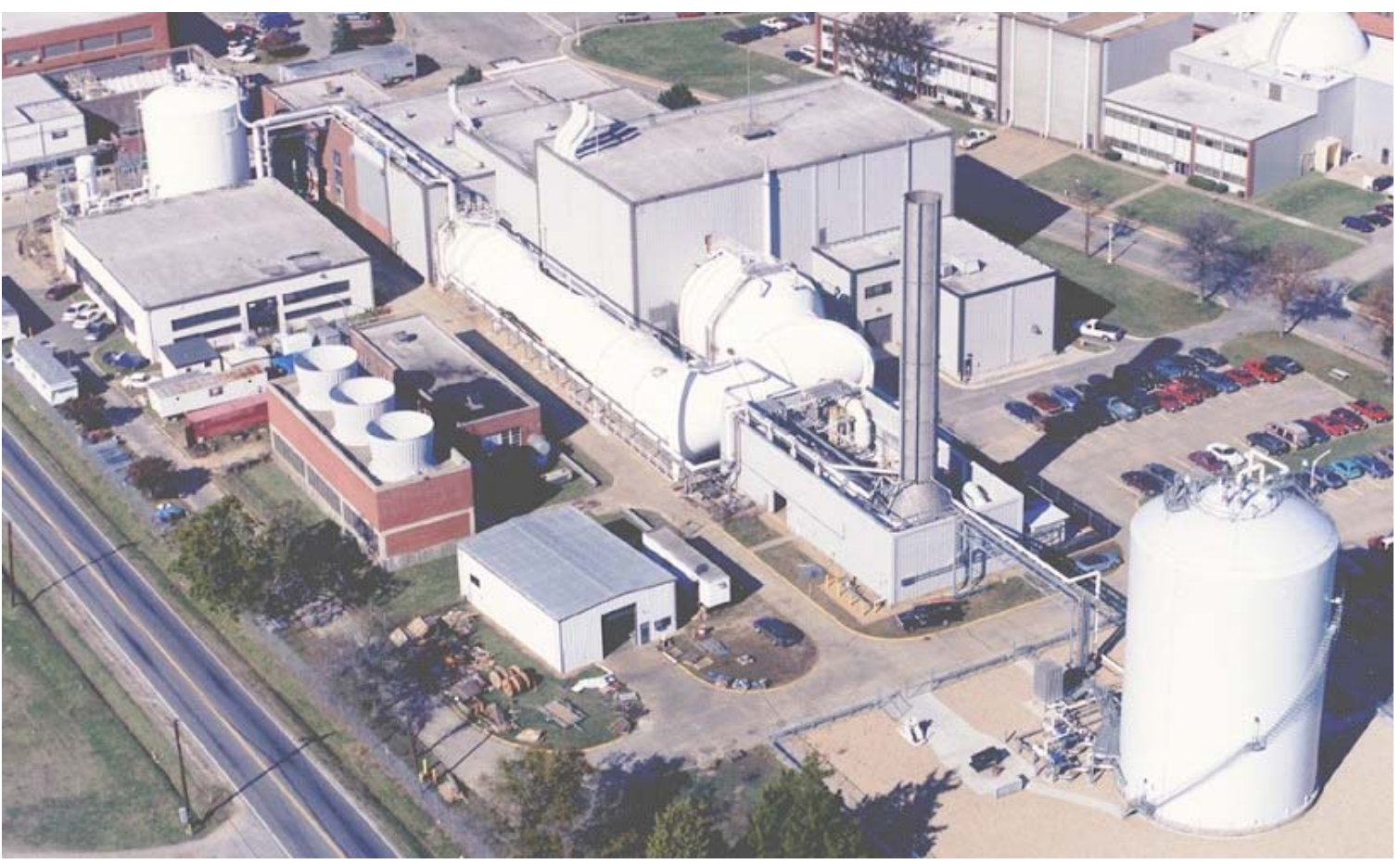

Figure 1. Aerial View of the National Transonic Facility.

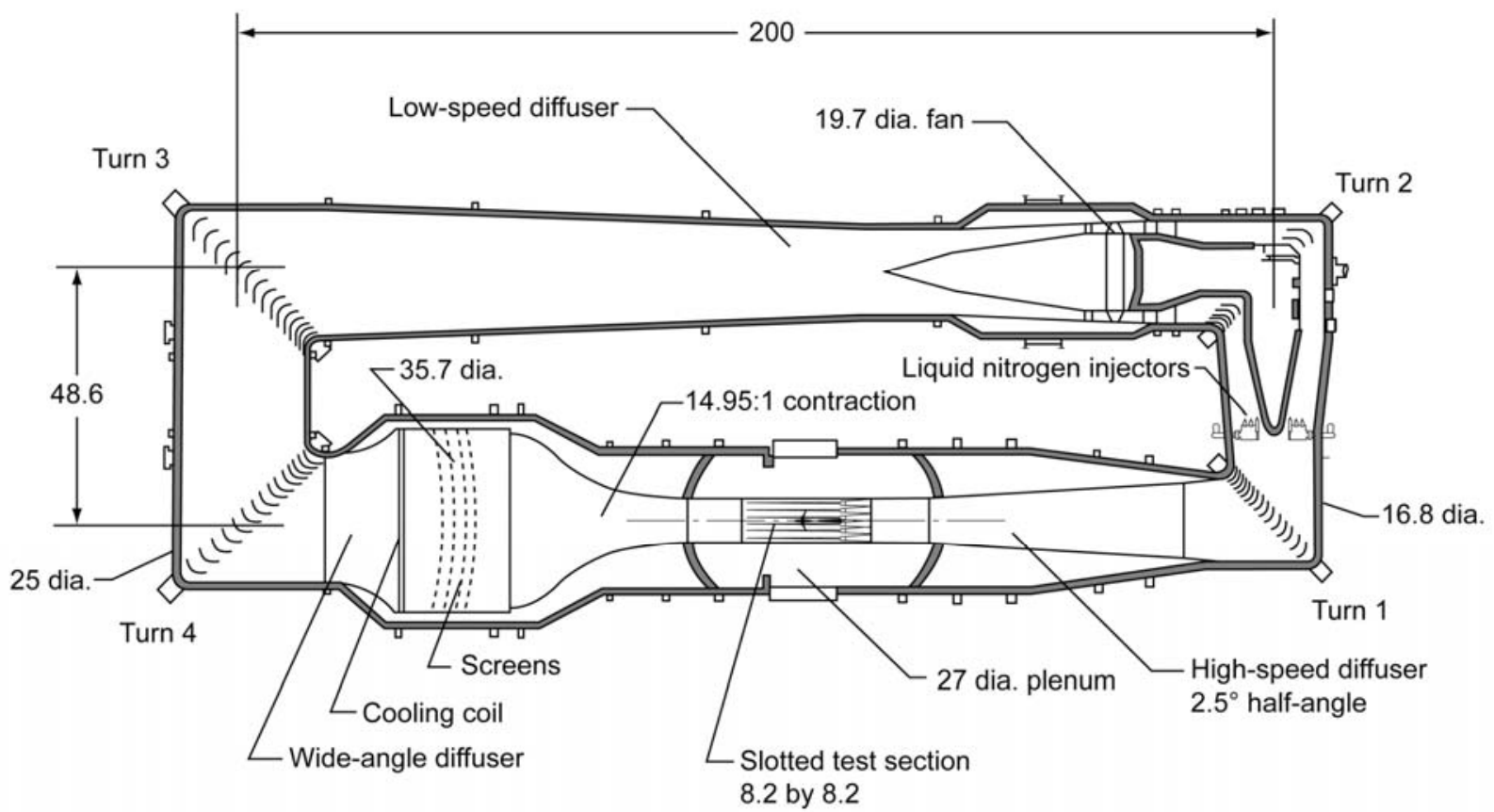

Figure 2. Sketch of the National Transonic Facility tunnel circuit. Linear dimensions are given in feet.

8

American Institute of Aeronautics and Astronautics 

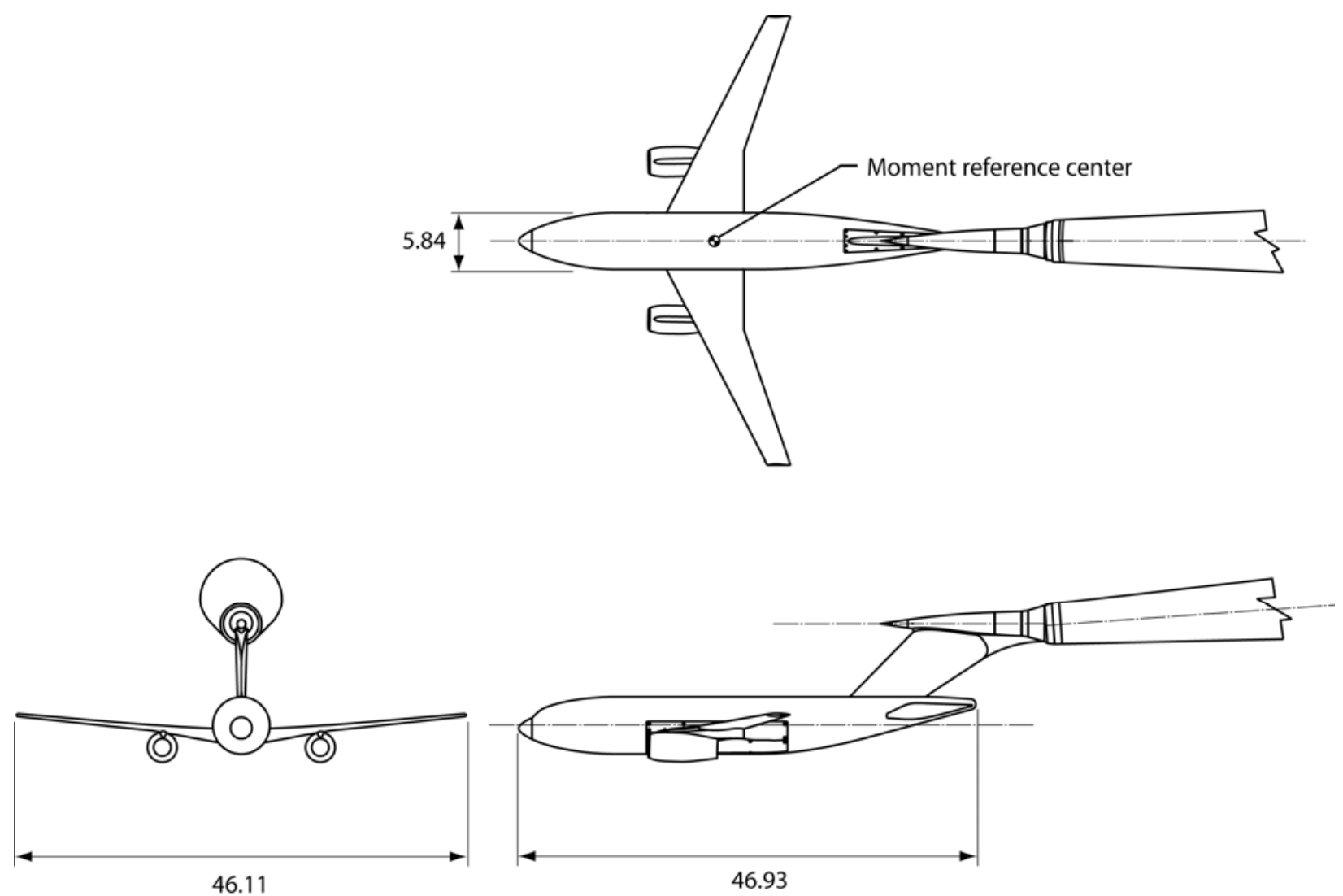

Figure 3. Three-view sketch of the DLR-F6 model. Dimensions are given in inches.

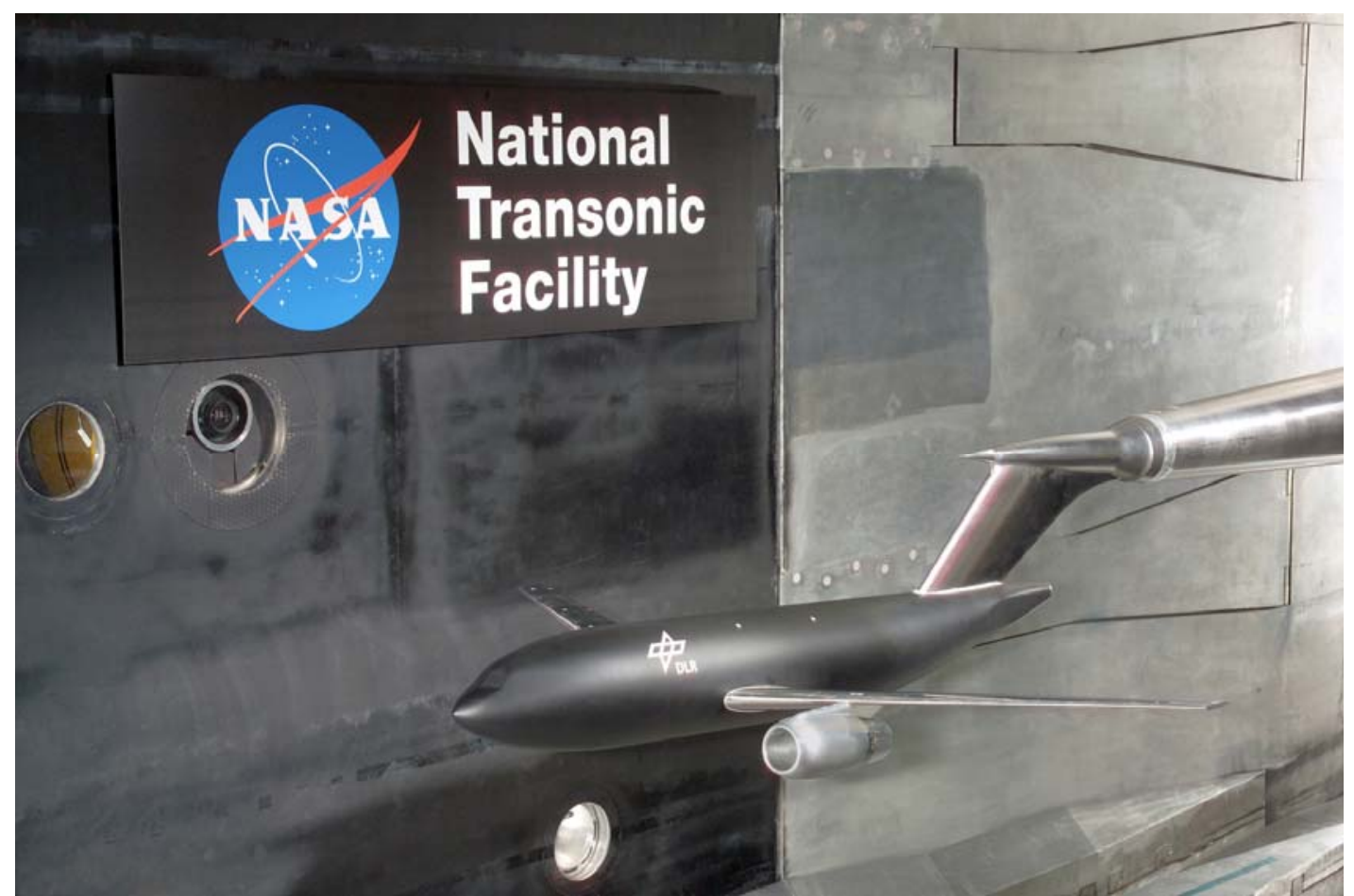

Figure 4. Photograph of the DLR-F6 model mounted in the test section of the National Transonic Facility. 


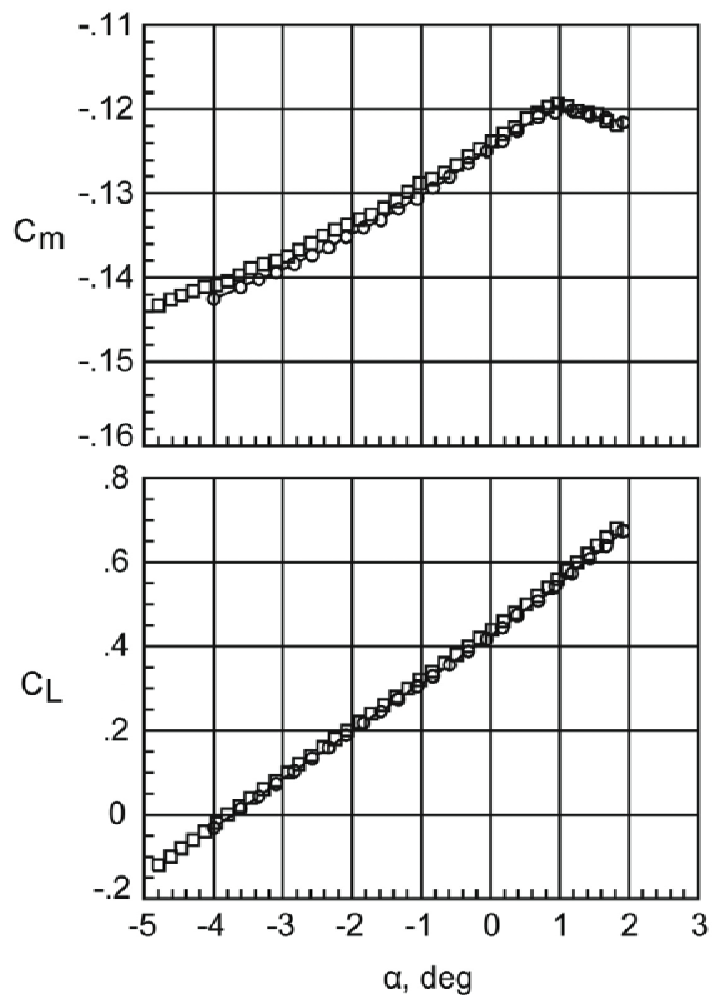

\begin{tabular}{|cccc|}
\hline & Run & Facility & $\mathrm{Re}_{\mathrm{c}} \times 10^{-6}$ \\
$\circ$ & 51 & NTF & 3.0 \\
$\square$ & 375 & ONERA & 3.0 \\
\hline
\end{tabular}

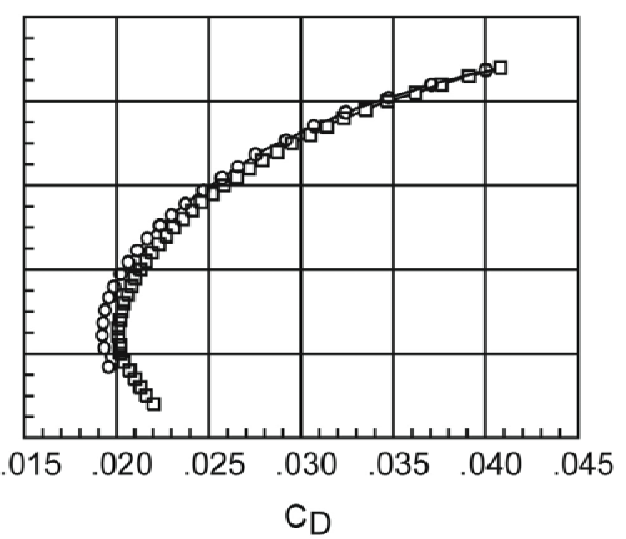

Figure 5. Comparison of NTF and ONERA data for the wing-body configuration (Ref. 10).

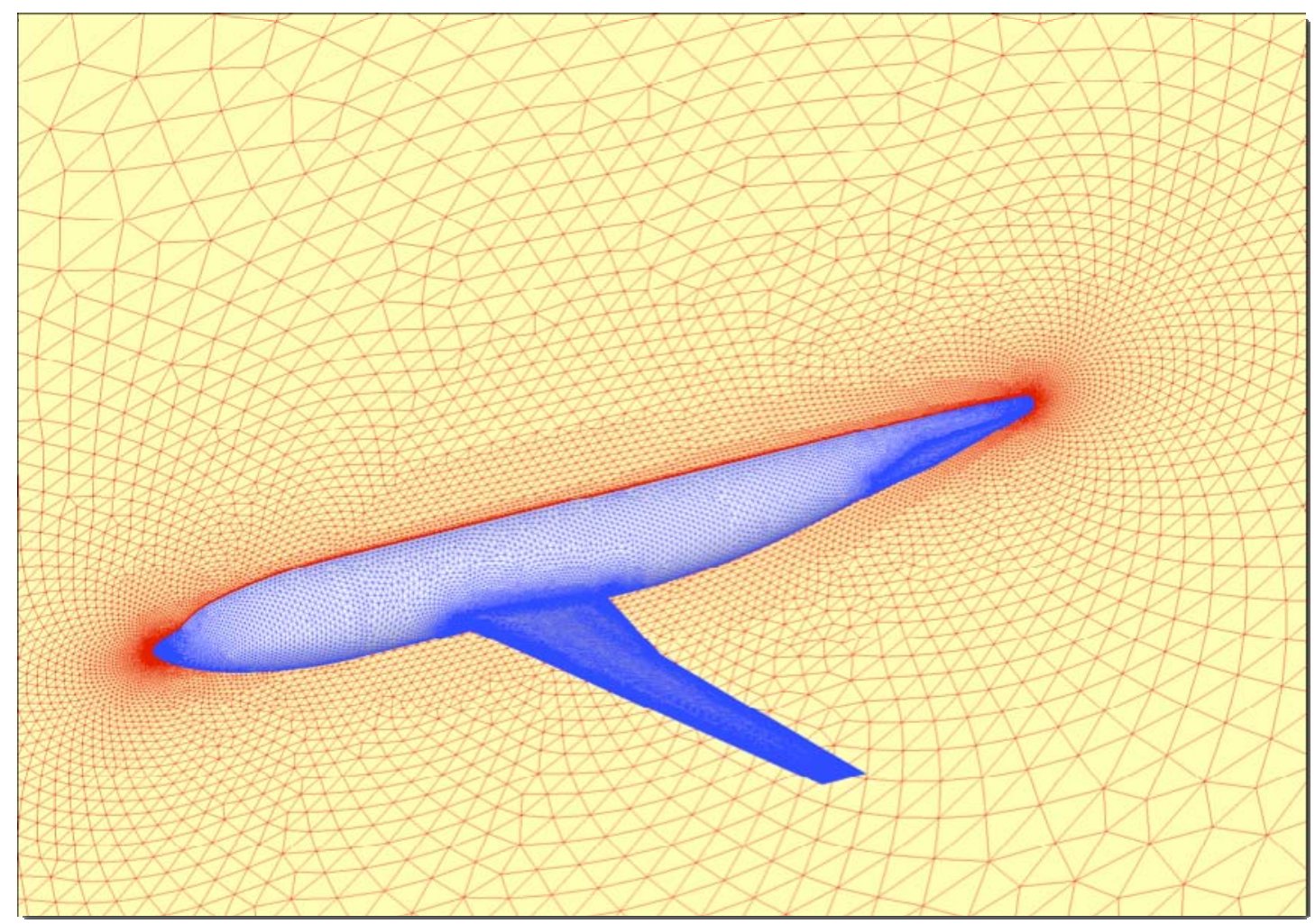

Figure 6. Isolated wing-body configuration surface mesh.

American Institute of Aeronautics and Astronautics 


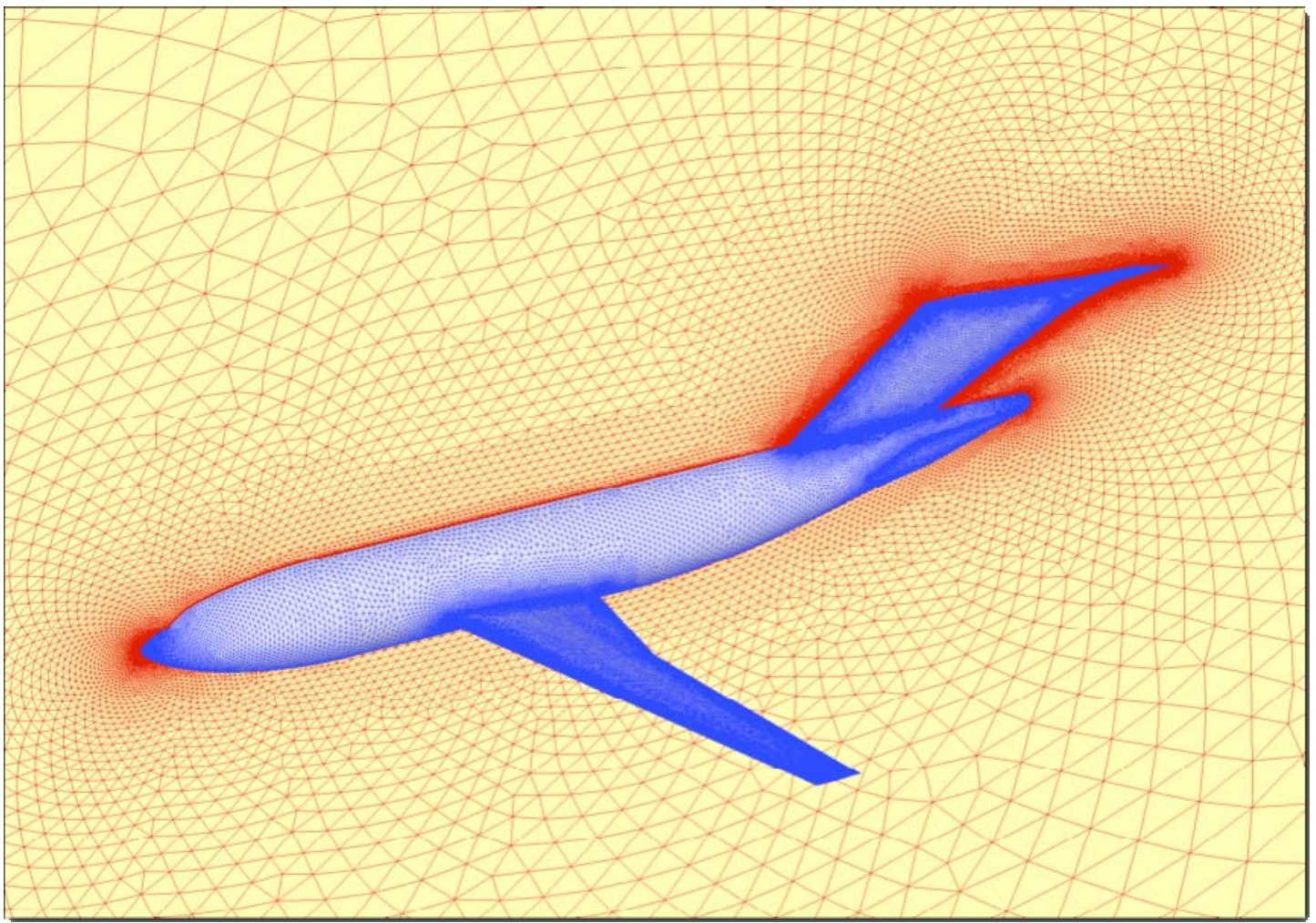

Figure 7. Wing-body with blade configuration surface mesh.

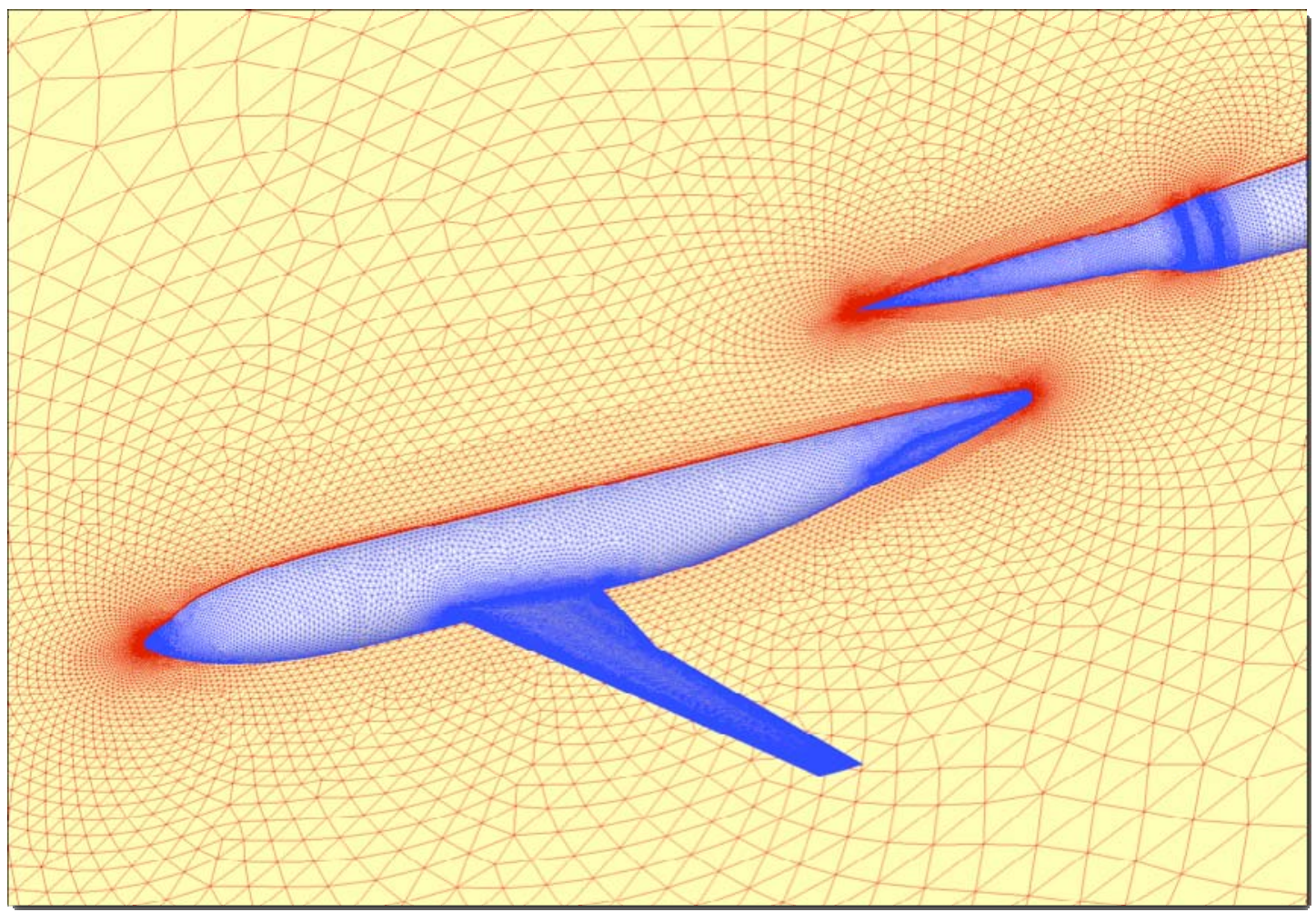

Figure 8. Wing-body with sting configuration surface mesh.

American Institute of Aeronautics and Astronautics 


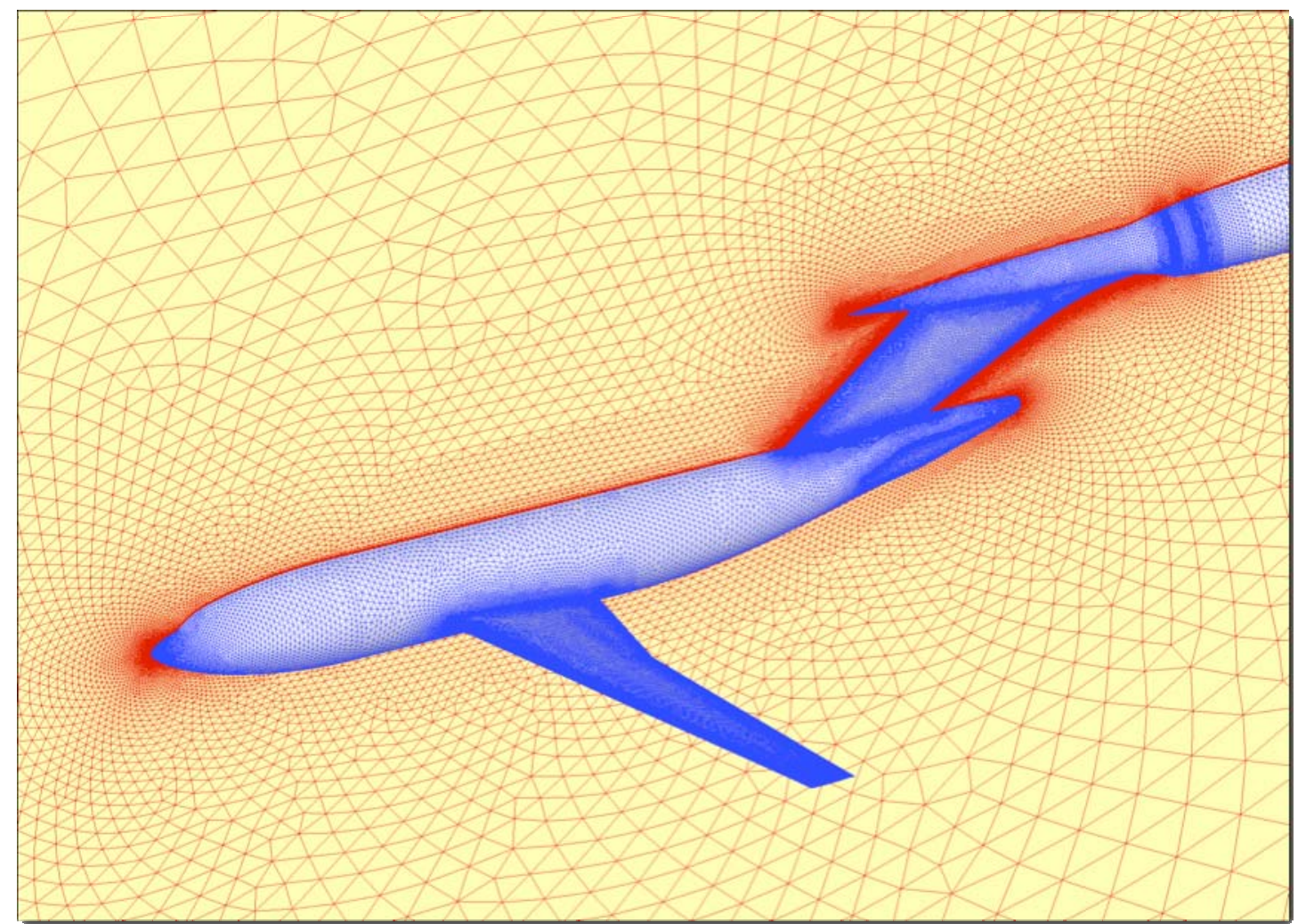

Figure 9. Wing-body with full support system (blade and sting) configuration surface mesh.
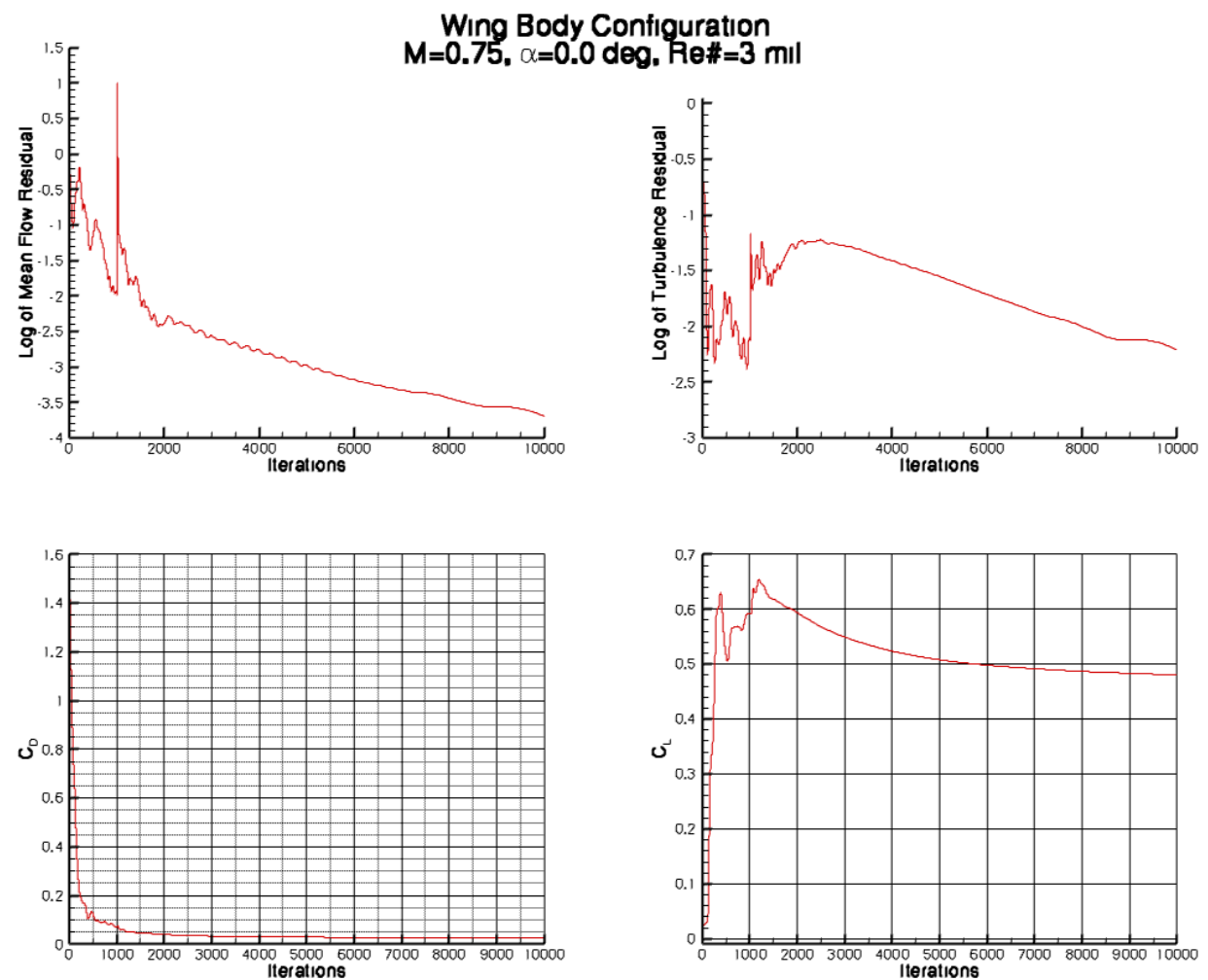

Figure 10. Wing-body convergence history, $M=0.75, \alpha=0.0 \mathrm{deg}, \operatorname{Re}_{c}=3$ million.

American Institute of Aeronautics and Astronautics 

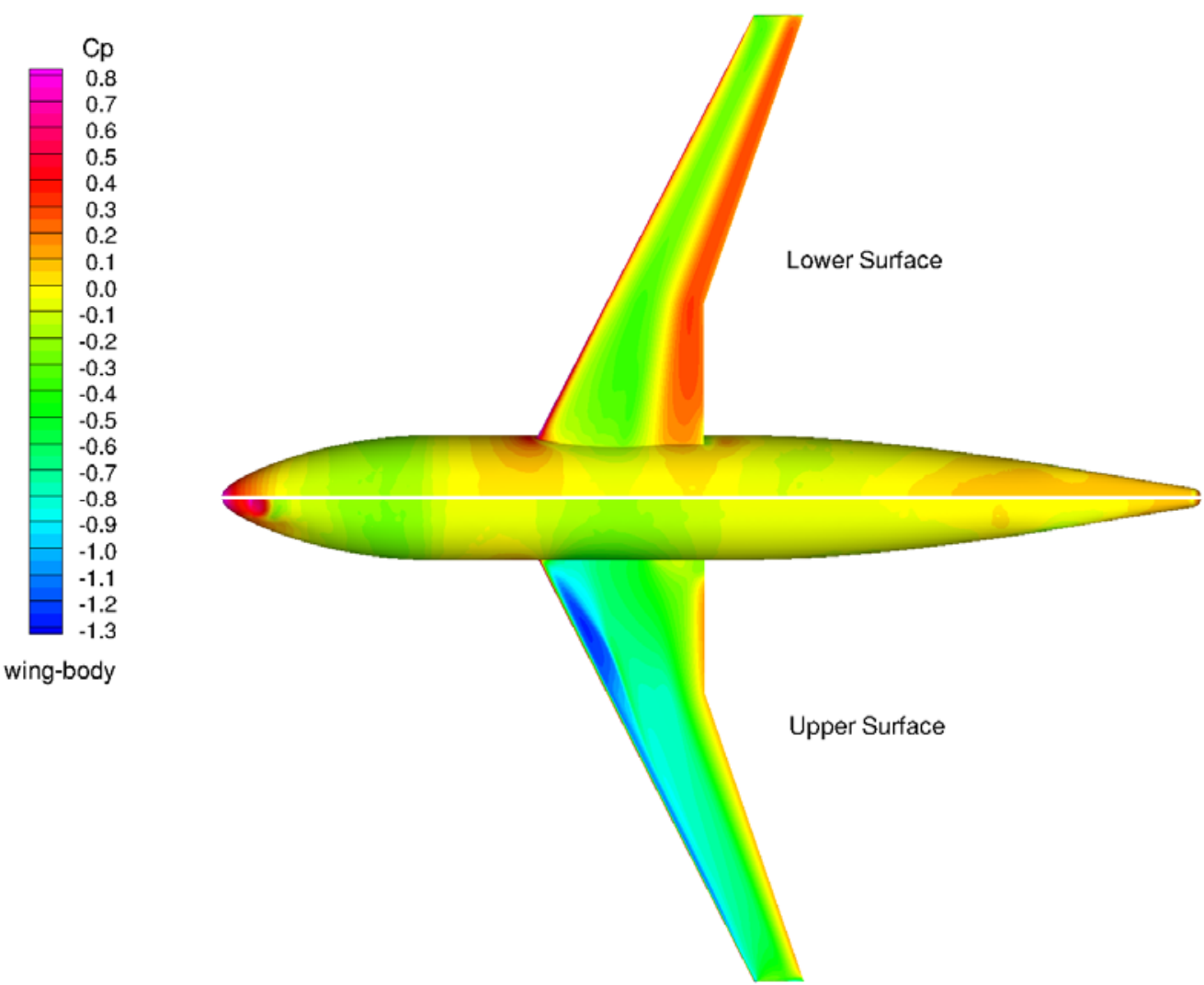

Figure 11. Surface pressure coefficient contours, wing-body configuration.
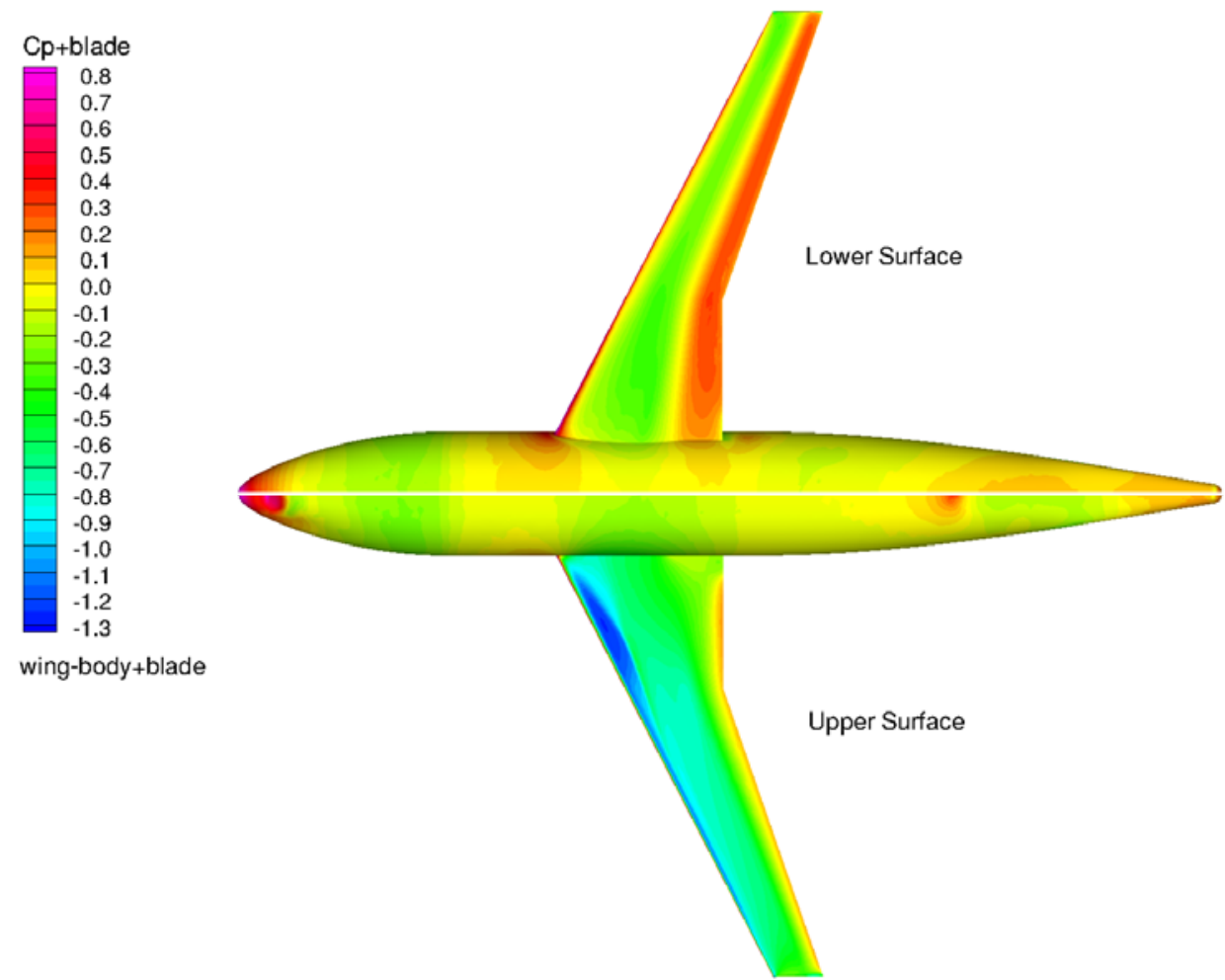

Figure 12. Surface pressure coefficient contours, wing-body with blade configuration. 13

American Institute of Aeronautics and Astronautics 

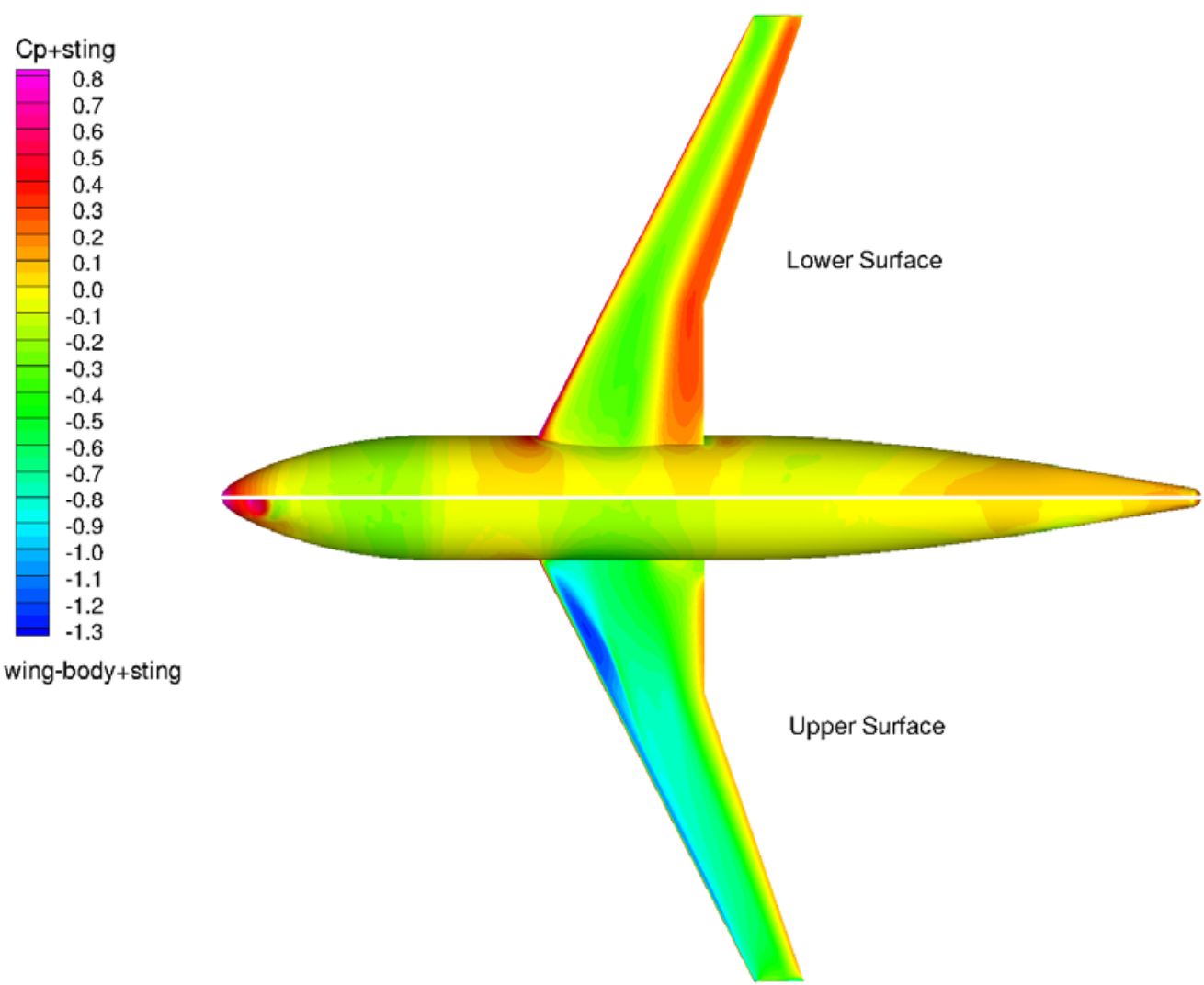

Figure 13. Surface pressure coefficient contours, wing-body with sting configuration.
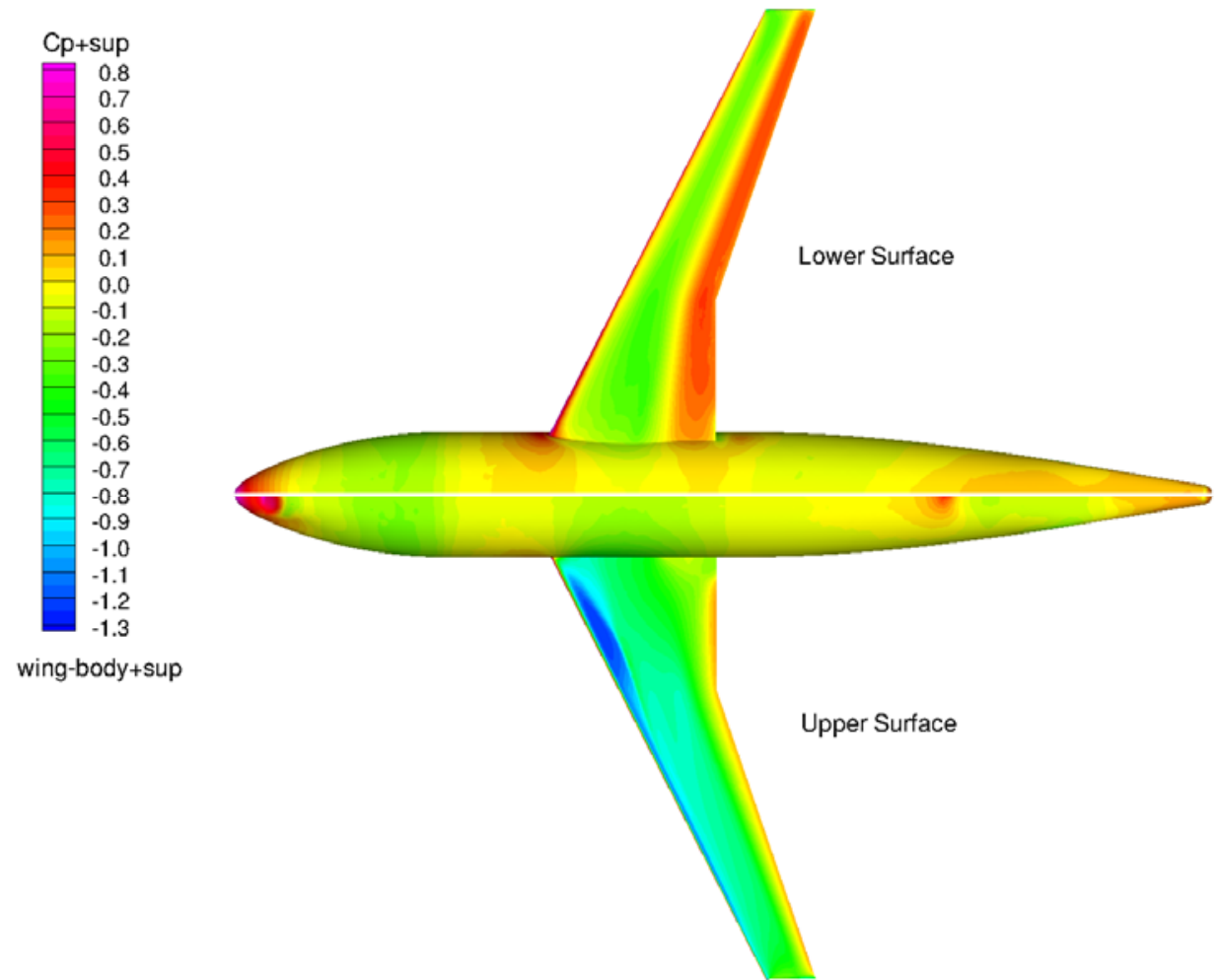

Figure 14. Surface pressure coefficient contours, wing-body with full support configuration. 14

American Institute of Aeronautics and Astronautics 

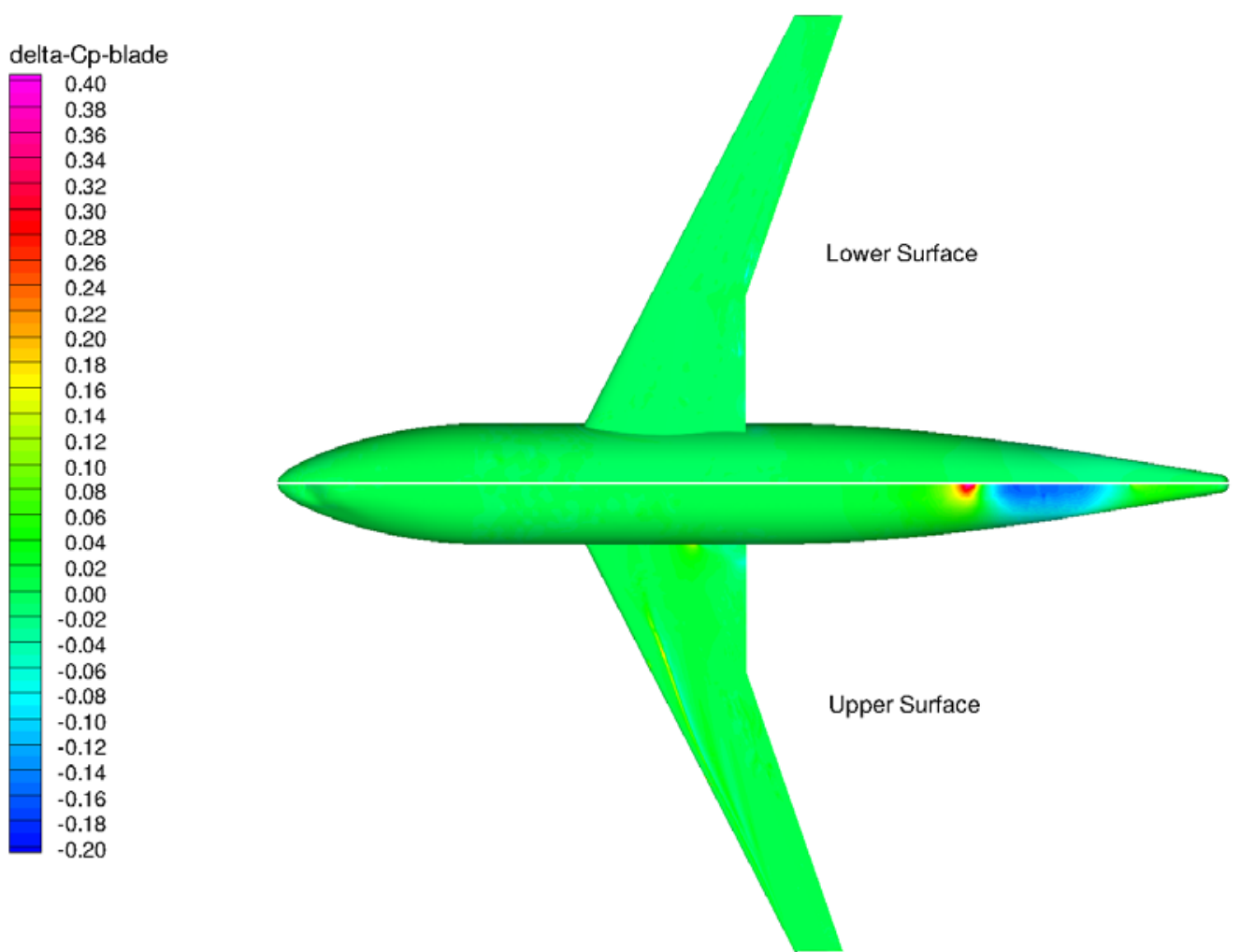

Figure 15. $\Delta \mathbf{C}_{P}$ contours for the wing-body with blade configuration.
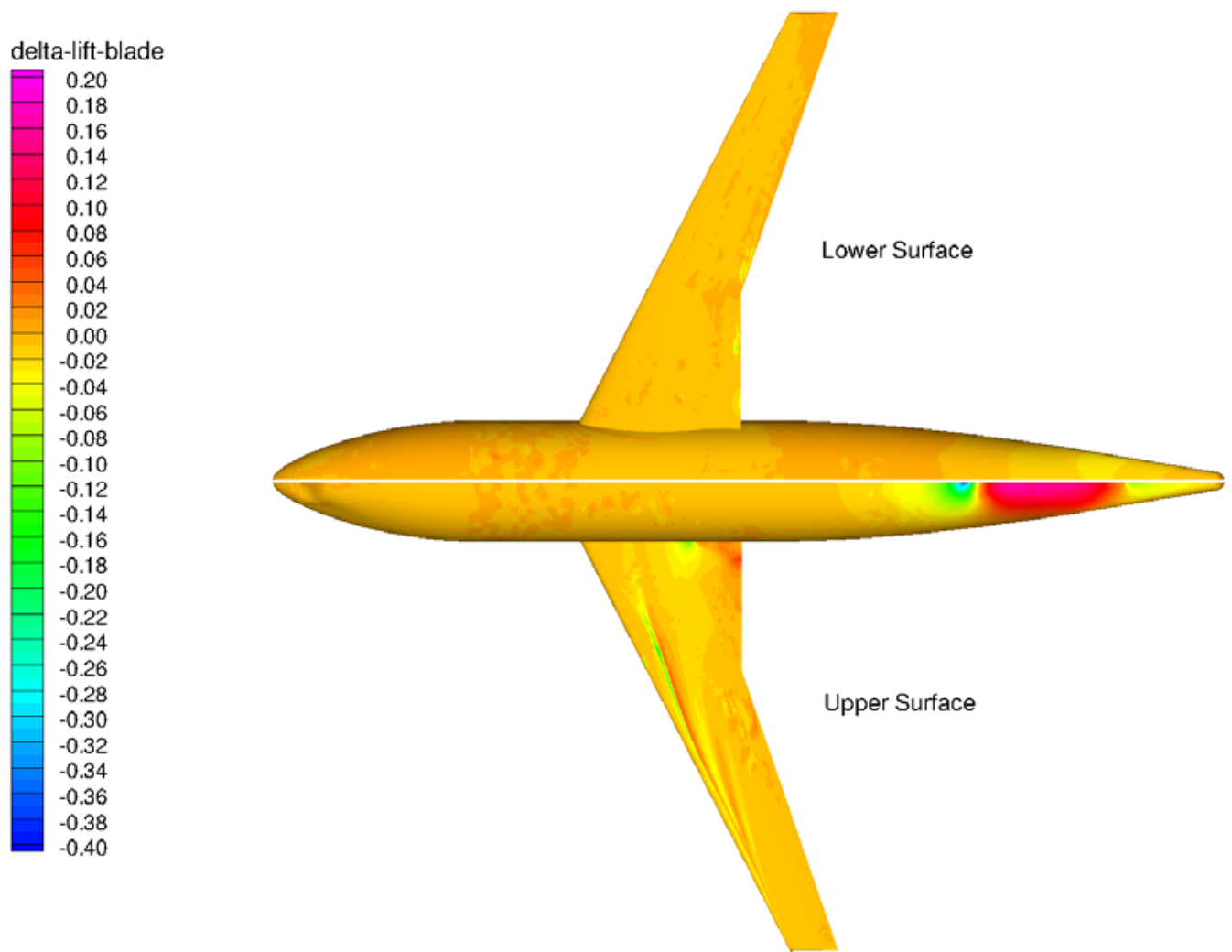

Figure 16. $\Delta C_{L}$ contours for the wing-body with blade configuration.

15

American Institute of Aeronautics and Astronautics 

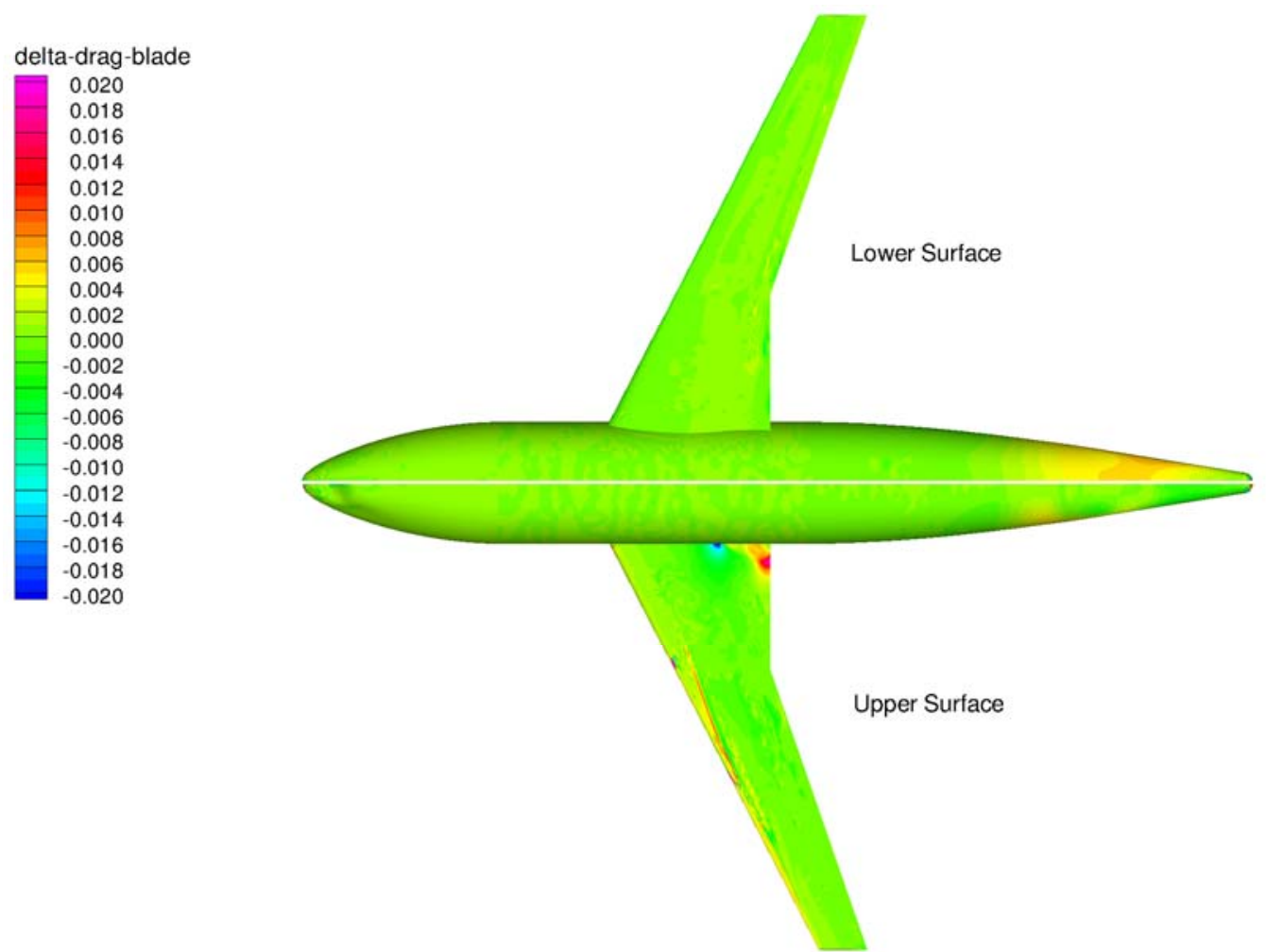

Figure 17. $\Delta C_{D}$ contours for the wing-body with blade configuration.
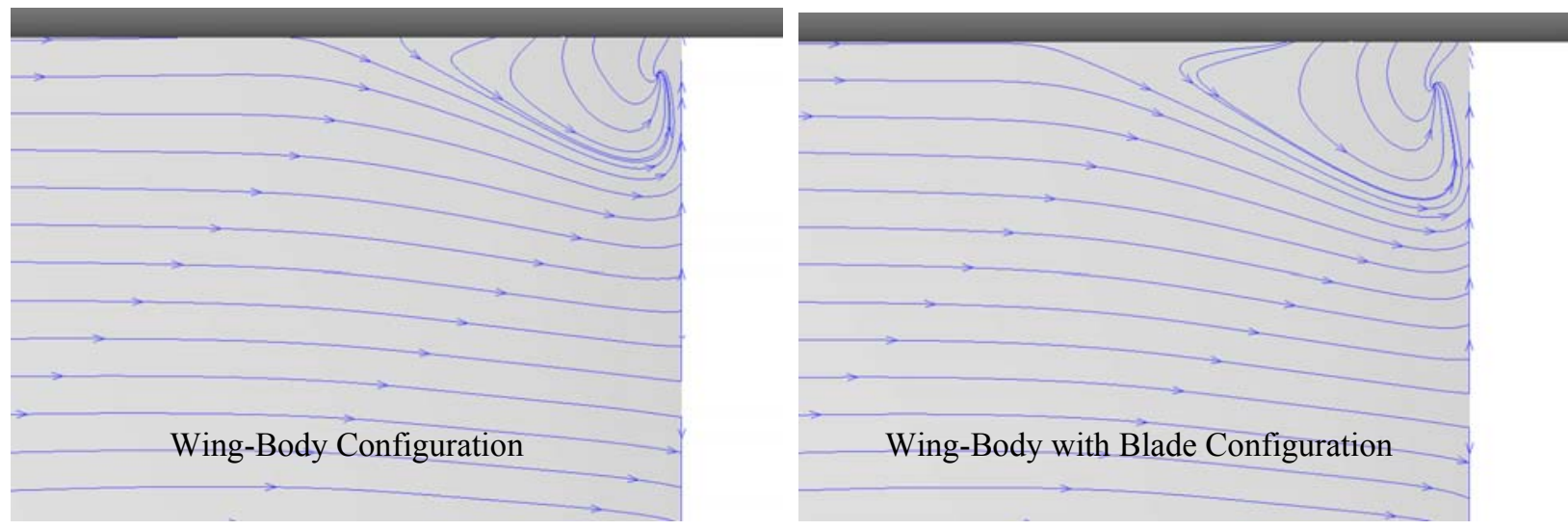

Figure 18. Wing-body junction area surface streamlines near trailing edge. 

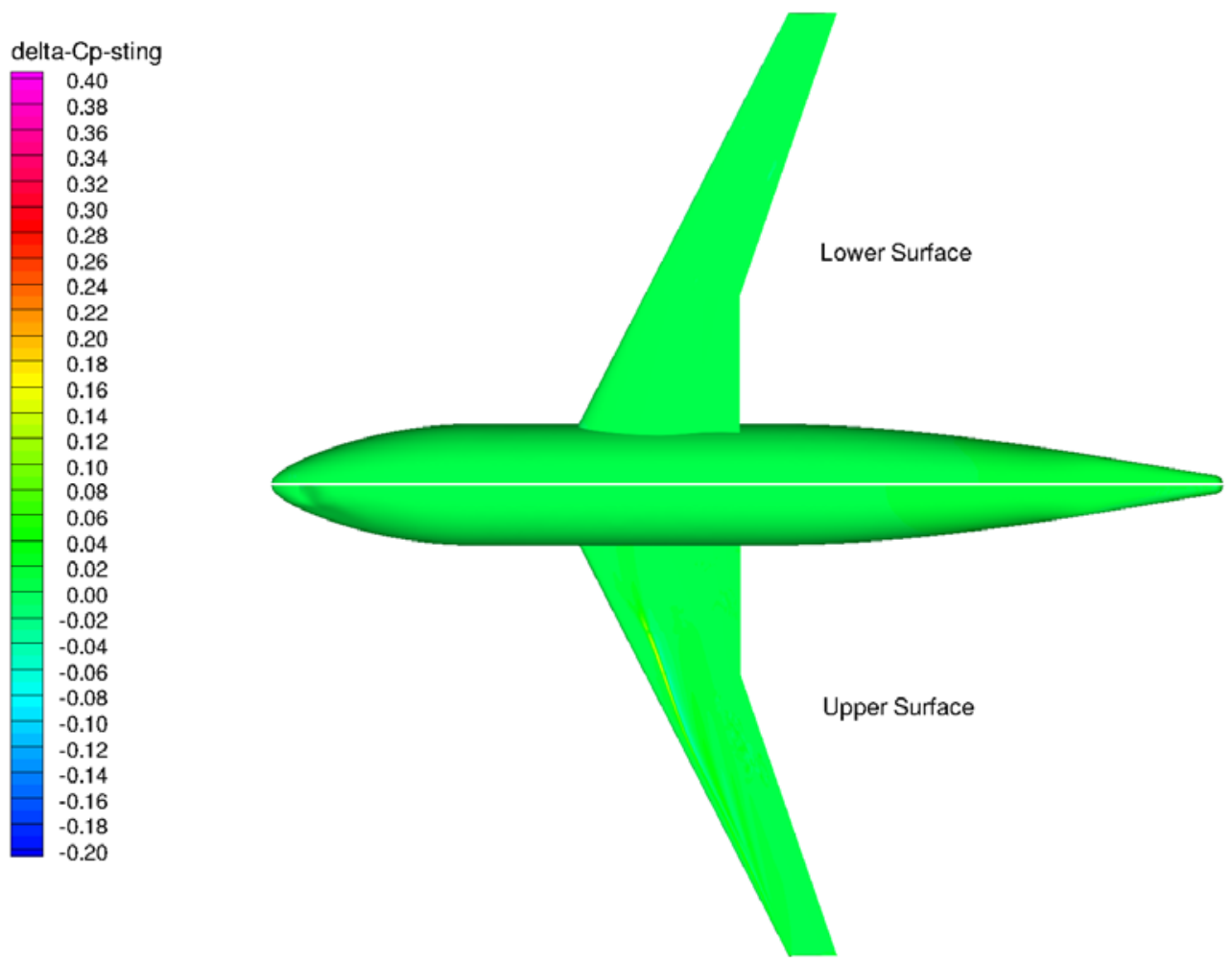

Figure 19. $\Delta \mathrm{C}_{\mathrm{P}}$ contours for the wing-body with sting configuration.
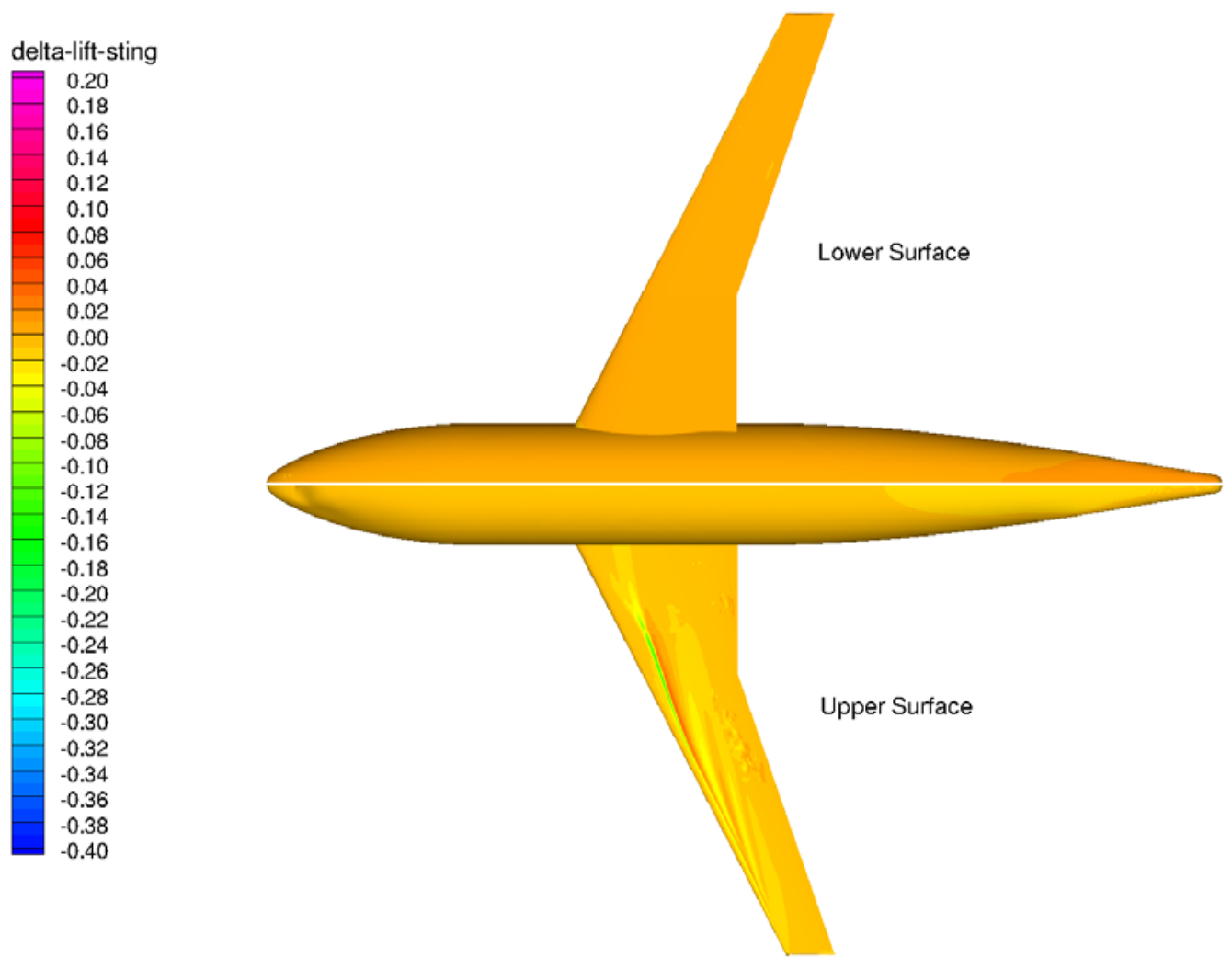

Figure 20. $\Delta \mathrm{C}_{\mathrm{L}}$ contours for the wing-body with sting configuration.

American Institute of Aeronautics and Astronautics 

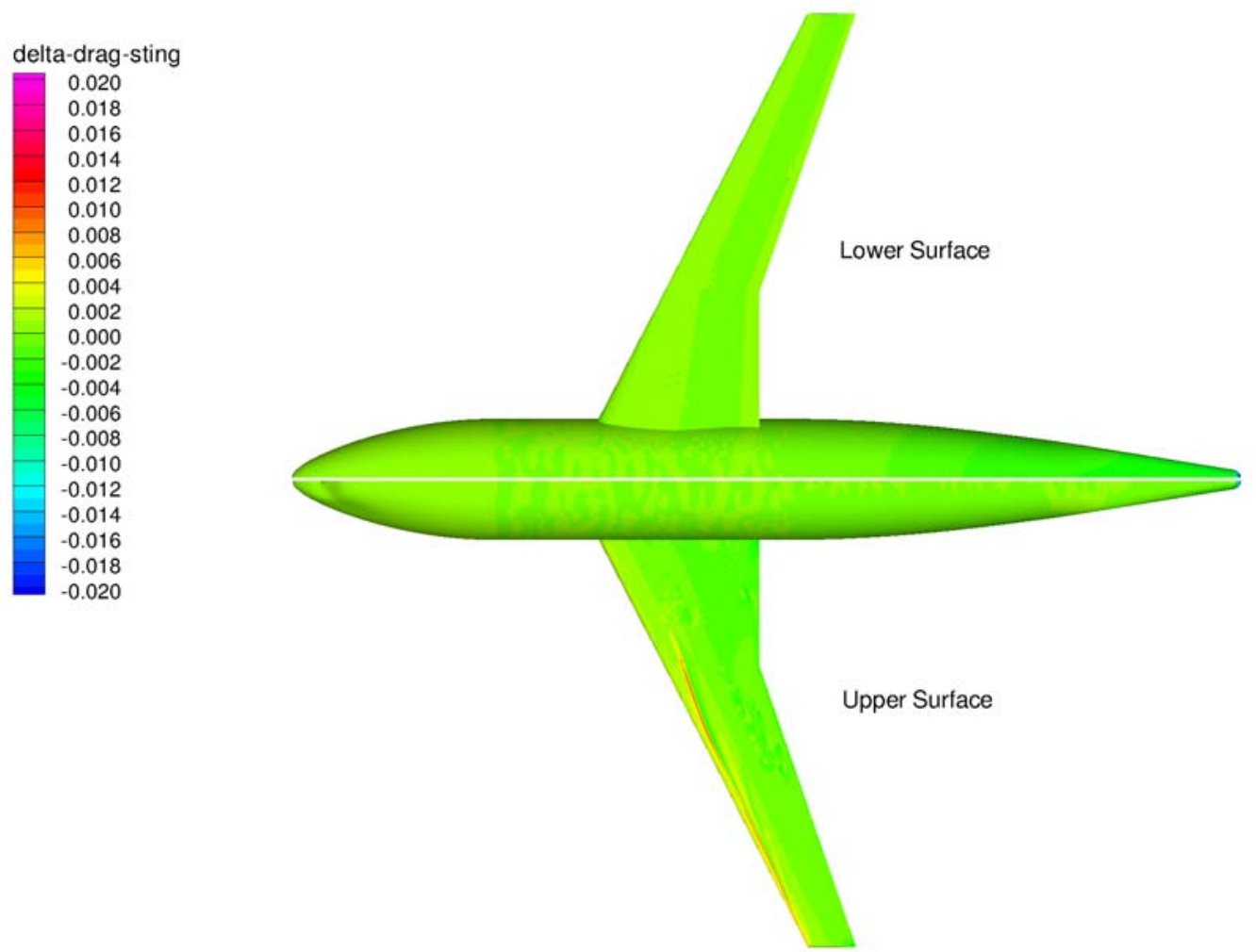

Figure 21. $\Delta C_{D}$ contours for the wing-body with sting configuration.

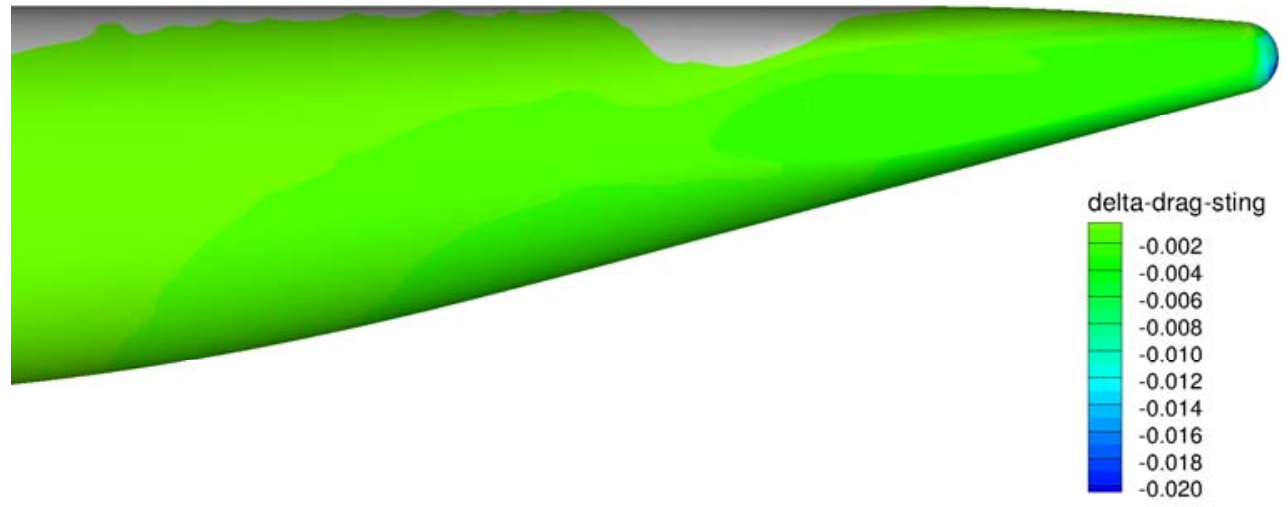

Figure 22. $\Delta \mathbf{C}_{\mathrm{D}}$ contours in the tail cone region (side view), wing-body with sting configuration. (Note: contour scale has been clipped to only show drag reduction) 


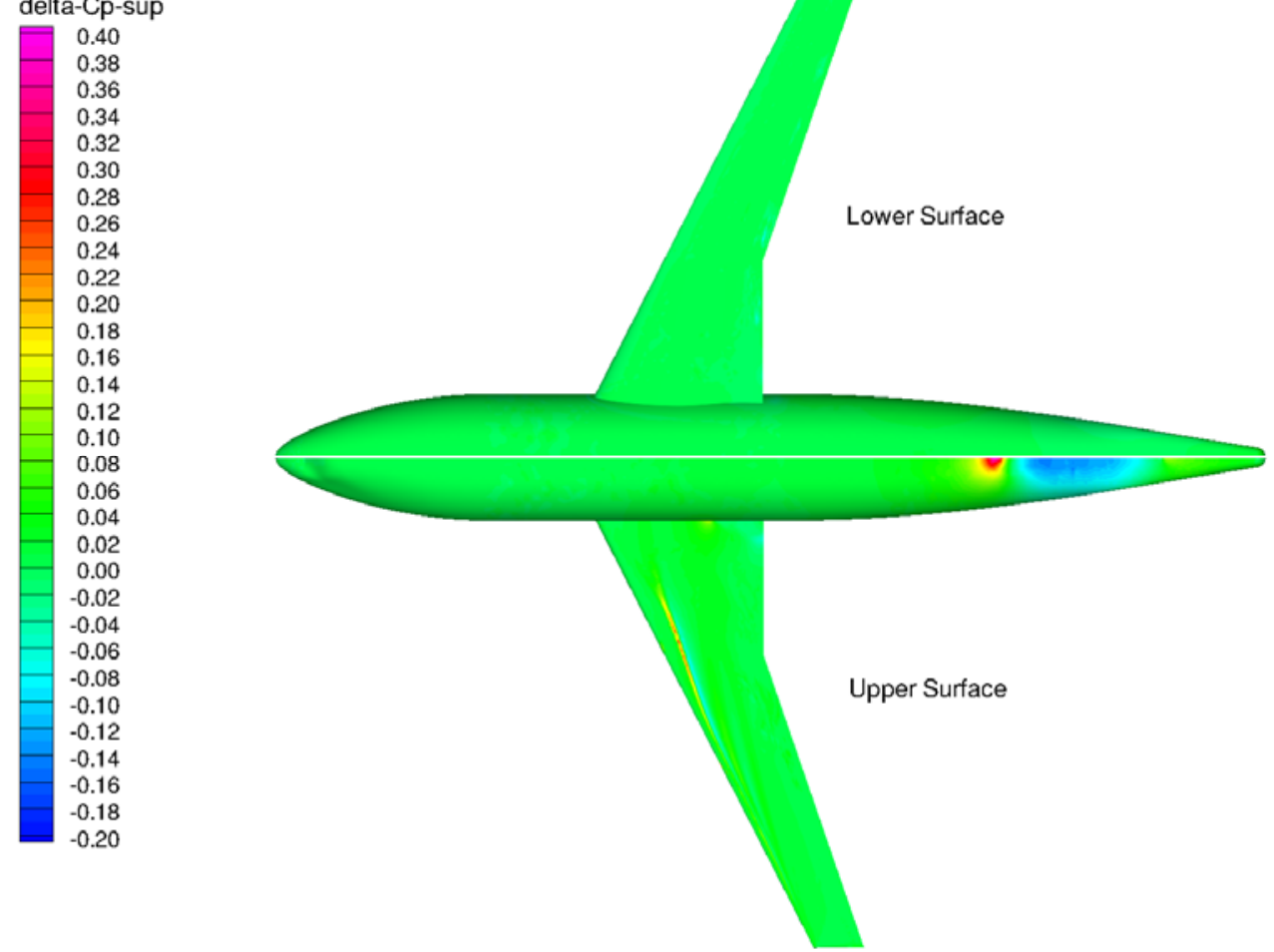

Figure 23. $\Delta \mathrm{C}_{\mathrm{P}}$ contours for the wing-body with full support configuration.
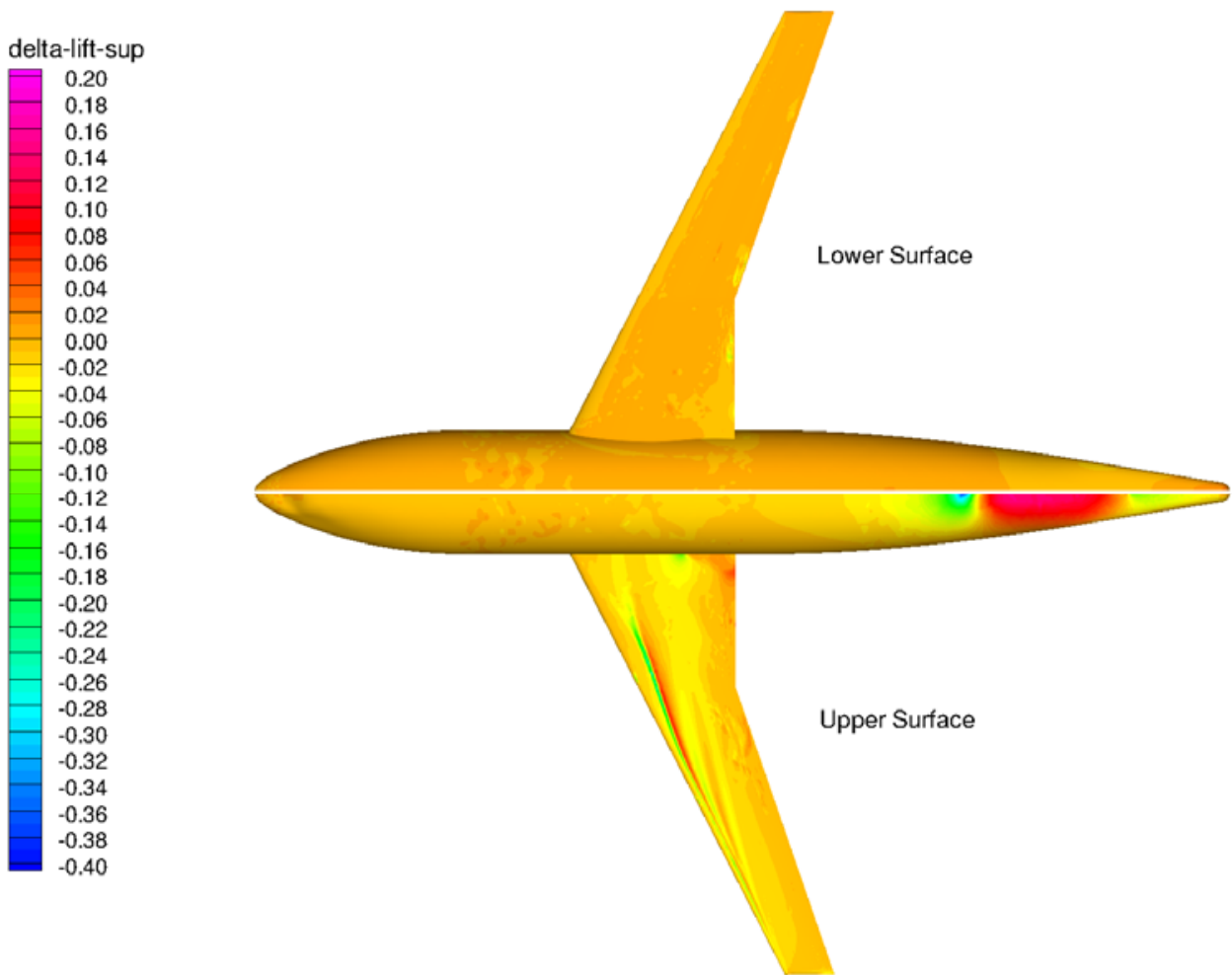

Figure 24. $\Delta C_{L}$ contours for the wing-body with full support configuration. 

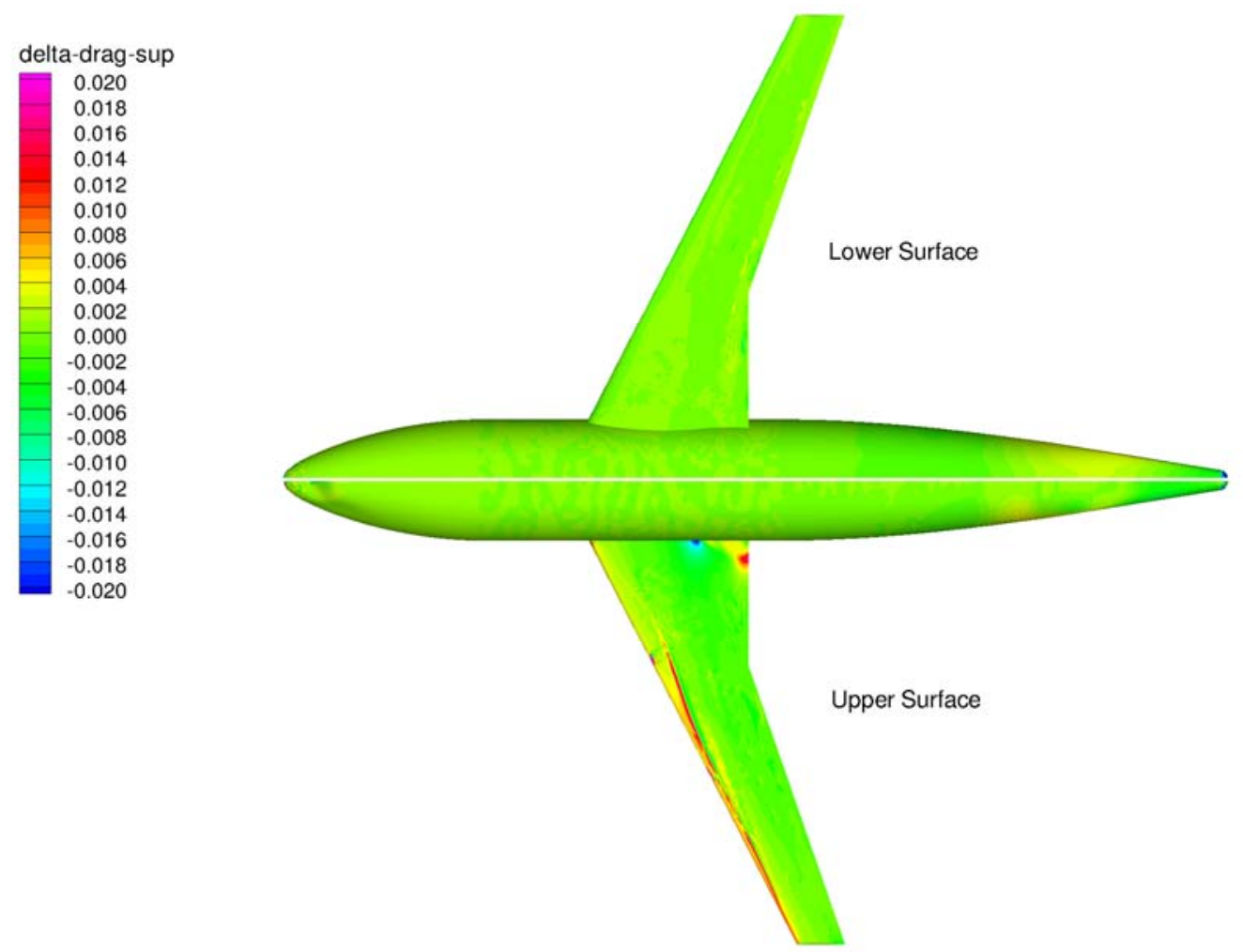

Figure 25. $\Delta \mathbf{C}_{\mathrm{D}}$ Contours for the wing-body with full support configuration. 